\title{
Hypersonic Boundary Layer Measurements with Variable Blowing Rates Using Molecular Tagging Velocimetry
}

\author{
Brett F. Bathel ${ }^{1}$ and Paul M. Danehy ${ }^{2}$ \\ NASA Langley Research Center, Hampton, Virginia, 23681-2199 \\ Craig T. Johansen ${ }^{3}$ \\ University of Calgary, Calgary, Alberta, Canada, T2N 1N4 \\ Stephen B. Jones ${ }^{4}$ \\ NASA Langley Research Center, Hampton, Virginia, 23681-2199 \\ and \\ Christopher P. Goyne \\ University of Virginia, Charlottesville, Virginia, 22904
}

\begin{abstract}
Measurements of mean and instantaneous streamwise velocity profiles in a hypersonic boundary layer with variable rates of mass injection (blowing) of nitrogen dioxide $\left(\mathrm{NO}_{2}\right)$ were obtained over a 10-degree half-angle wedge model. The $\mathrm{NO}_{2}$ was seeded into the flow from a slot located $29.4 \mathrm{~mm}$ downstream of the sharp leading edge. The top surface of the wedge was oriented at a 20 degree angle in the Mach 10 flow, yielding an edge Mach number of approximately 4.2. The streamwise velocity profiles and streamwise fluctuating velocity component profiles were obtained using a three-laser $\mathrm{NO}_{2} \rightarrow \mathrm{NO}$ photolysis molecular tagging velocimetry method. Observed trends in the mean streamwise velocity profiles and profiles of the fluctuating component of streamwise velocity as functions of the blowing rate are described. An effort is made to distinguish between the effect of blowing rate and wall temperature on the measured profiles. An analysis of the mean velocity profiles for a constant blowing rate is presented to determine the uncertainty in the measurement for different probe laser delay settings. Measurements of streamwise velocity were made to within approximately $120 \mu \mathrm{m}$ of the model surface. The streamwise spatial resolution in this experiment ranged from $0.6 \mathrm{~mm}$ to $2.6 \mathrm{~mm}$. An improvement in the spatial precision of the measurement technique has been made, with spatial uncertainties reduced by about a factor of 2 compared to previous measurements. For the quiescent flow calibration measurements presented, uncertainties as low as $2 \mathrm{~m} / \mathrm{s}$ are obtained at $95 \%$ confidence for long delay times $(25 \mu \mathrm{s})$. For the velocity measurements obtained with the wind tunnel operating, average single-shot uncertainties of less than $44 \mathrm{~m} / \mathrm{s}$ are obtained at $95 \%$ confidence with a probe laser delay setting of $1 \mu \mathrm{s}$. The measurements were performed in the 31-inch Mach 10 Air Tunnel at the NASA Langley Research Center.
\end{abstract}

\section{Introduction}

L AMINAR-to-turbulent transition affects several aspects of hypersonic vehicle design ranging from the control of flight vehicles to the efficiency of a fuel-air mixing process in high-speed combustion applications. Understanding the nature and cause of transition will aid in the development of predictive computational capabilities that will identify the onset and location of transition based upon the driving physical mechanisms. One of the

${ }^{1}$ Graduate Student, University of Virginia and NASA Graduate Co-op, Hampton, Virginia, AIAA Student Member.

${ }^{2}$ Research Scientist, Advanced Sensing and Optical Measurement Branch, MS 493, AIAA Associate Fellow.

${ }^{3}$ Assistant Professor, Mechanical and Manufacturing Engineering, AIAA Member.

${ }^{4}$ Research Technician, Advanced Sensing and Optical Measurement Branch, MS 493.

${ }^{5}$ Research Associate Professor, Mechanical and Aerospace Engineering, Aerospace Research Laboratory, PO Box 400248, AIAA Associate Fellow. 
primary flow parameters of interest in the development of such predictive capabilities is the velocity field. All three components of velocity appear in each equation making up the full Navier-Stokes equations (including continuity, momentum, and energy), which govern the gas dynamics under study. In hypersonic laminar boundary layer flows, the aerodynamic heating imparted to the wall is related to the edge velocity ${ }^{1}, q_{w}=\rho_{e} U_{e} C_{H}\left(h_{a w}-h_{w}\right)$, where $q_{w}$ is the surface heat transfer, $\rho_{e}$ the edge density, $U_{e}$ the edge velocity, $C_{H}$ the Stanton number, and $\mathrm{h}_{\mathrm{w}}$ and $\mathrm{h}_{\mathrm{aw}}$ are the gas enthalpies based on the wall temperature and adiabatic wall temperature, respectively. In a hypersonic laminar boundary layer, when transition to turbulence occurs, wall heating at the site of transition can often spike to a factor of three or greater than that of the laminar baseline heating level. ${ }^{2}$ Basic stability analyses, which provide a fundamental understanding about the transition process, often rely on knowledge of the behavior of the mean and fluctuating components of streamwise velocity in order to begin to formulate predictions for transition. ${ }^{3,4}$

One experimental method currently being developed at NASA Langley Research Center to study the hypersonic laminar-to-turbulent transition process is molecular tagging velocimetry (MTV). A single-laser excitation version of the technique has demonstrated the capability to provide both mean and instantaneous velocity profiles in a strictly laminar boundary layer flow. ${ }^{5,6}$ Recently, a three-laser version of the technique, whose development is described in Refs. 7-12, has been demonstrated to be capable of providing measurements of velocity in a transitional boundary layer flow obtained in a large-scale hypersonic test facility. ${ }^{13}$ However, in the initial demonstration (Ref. 13) of the three-laser technique, low signal-to-noise levels resulting from a combination of insufficient probe laser energies, laser alignment issues, laser light scattering problems, and poor $\mathrm{NO}_{2}$-to- $\mathrm{NO}$ conversion efficiency limited the accuracy and precision of the velocity measurements.

The purpose of this paper is to provide an improved description of the capabilities of the three-laser, $\mathrm{NO}_{2}$-to- $\mathrm{NO}$ photodissociation MTV technique as applied to hypersonic boundary layer velocity measurement in a large-scale hypersonic test facility. The description of the technique consists of four parts. First, this paper provides a brief discussion of the changes incorporated into the experimental setup based upon the recommendations in Ref. 13. Second, velocity data obtained in a relatively quiescent flowfield using (i) several probe laser delays at constant pressure and (ii) a constant probe laser delay for several static pressures are analyzed to characterize properties such as uncertainty and data yield in the same fashion as presented in Ref. 13. Third, velocity data obtained in a laminar hypersonic boundary layer using three different probe laser delays are analyzed to determine uncertainty behavior and experimental repeatability as functions of the delay setting. Fourth, and of primary importance in this paper, a description of the behavior of the hypersonic boundary layer as a function of mass injection (blowing) rate, $\dot{\mathrm{m}}_{\text {Blowing, }}$ of $\mathrm{NO}_{2}$ gas is provided. This description includes an analysis of the mean and fluctuating behavior of streamwise velocity profiles as well as a characterization of data yield, all as functions of the blowing rate.

In the experiment described in this paper, which was a follow-on to the one described in Ref.13, we discovered that increasing blowing rate beyond that of previous experiments provided the adequate signal-to-noise levels necessary to make consistent measurements of velocity over the entire measurement region. This region included the extent to which the profiles spanned the thickness of the concentration boundary layer. The region also included a majority of profiles created via photolysis spaced at discrete intervals in the streamwise direction and along the centerline of the model. Although an increase in blowing rate resulted in an improvement in the signal-to-noise ratio - and hence data yield - across the measurement region, it eventually perturbed the mean and fluctuating streamwise velocity profiles at high enough flow rates. Based on the analysis presented in this paper, an optimal blowing rate is suggested (for the conditions tested) that ensures adequate signal-to-noise levels across the measurement region with minimal perturbation to the boundary layer.

\section{A. Wind Tunnel Facility}

\section{Experimental Setup}

The 31-Inch Mach 10 Air Tunnel is an electrically-heated blowdown facility located at NASA Langley Research Center in Hampton, Virginia, USA. The full details of this facility can be found in the paper by Micol ${ }^{14}$, a brief summary of which is provided here. The facility has a nominal Mach number of 10 and a 31 -inch square test section and operates on electrically heated, compressed air. Large windows, transparent in the ultraviolet down to approximately $190 \mathrm{~nm}$, form three walls (including top, side and bottom) of the test section with the fourth wall formed by the model injection system. The top window allows for the laser sheet to pass through the tunnel test section, while the side window allows for imaging of the flow region of interest. The model is attached at the rear to a sting, which is subsequently side-mounted to the fourth wall. Run durations for the experiments were typically one to two minutes. A single nominal facility stagnation pressure, $P_{0}$, of $4.96 \mathrm{MPa}$ (720 psia) was investigated. The nominal stagnation temperature, $T_{0}$, was $1000 \mathrm{~K}$ (1,800 Rankine). Based upon the stagnation conditions, the approximate freestream Mach number was 9.81, the approximate freestream velocity was $1400 \mathrm{~m} / \mathrm{s}$, the approximate 
freestream unit Reynolds number $\left(R e_{\infty}\right)$ was $3.28 \times 10^{6} \mathrm{~m}^{-1}$, the approximate freestream static pressure was $130 \mathrm{~Pa}$ $\left(18.9 \times 10^{-3} \mathrm{psi}\right)$, and the approximate freestream temperature was $51 \mathrm{~K}\left(92^{\circ} \mathrm{R}\right)$ 14.

\section{B. PLIF Imaging System}

A thorough description of the planar laser-induced fluorescence (PLIF) imaging and MTV system is provided in Ref. 13. Briefly, the system consists of two $\mathrm{Nd}$ :YAG-pumped dye laser systems in which the dye output is sum-frequency mixed to generate tunable UV light near $226 \mathrm{~nm}$. A $355 \mathrm{~nm}$ third-harmonic beam from one Nd:YAG laser and the two 226 $\mathrm{nm}$ beams from the dye lasers are used as

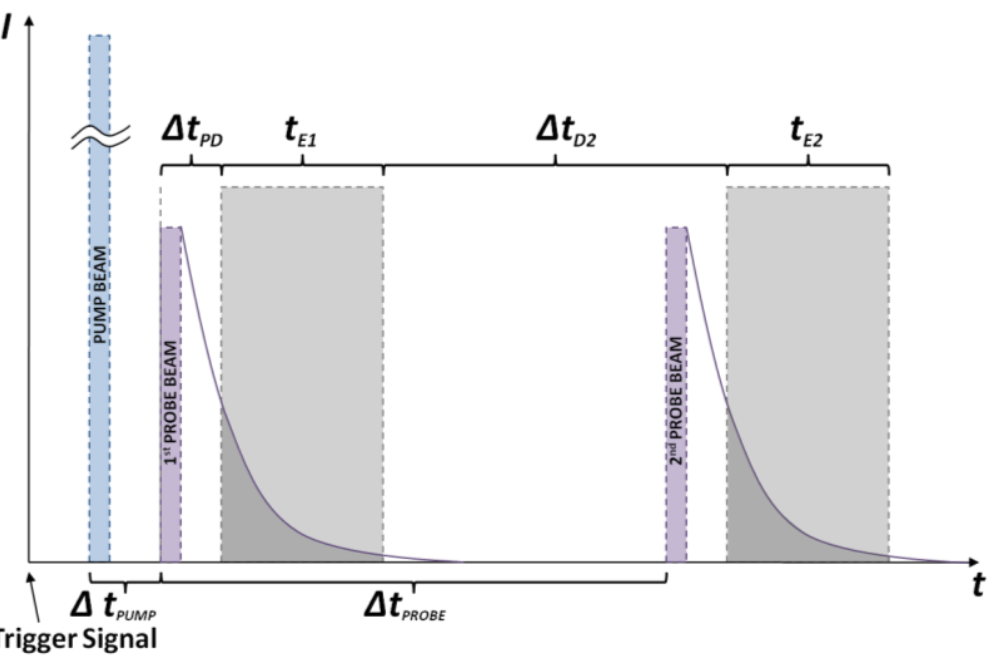

Figure 1. Timing schematic for three-laser $\mathrm{NO}_{2}$-to-NO photolysis experiment. pump beams (used to generate $\mathrm{NO}$ via $\mathrm{NO}_{2}$-to-NO photolysis) and probe laser sheets, respectively. The temporal relationship of these three beams is illustrated in Figure 1. The purpose of this section is to highlight significant changes to the previously described PLIF imaging system. Many of the changes described in this section are based on recommendations put forth in the previous paper.

The first significant change involved the timing of the dual-frame camera with respect to the timing of both the pump and probe beams. In the previous experiment, each camera exposure, $t_{E 1}$ and $t_{E 2}$, was timed such that they completely overlapped the $1^{\text {st }}$ and $2^{\text {nd }}$ probe beams, respectively. Unfortunately, scatter from the pump and probe beams off the bottom metallic surface of the model, observed on and through a quartz window insert (intended to reduce this scatter), diminished the signal-to-noise ratio observed in both exposures. Initially two filters, one for the $355 \mathrm{~nm}$ light (Semrock HG01 $254 \mathrm{~nm}$ filter: <1\% transmission below $236 \mathrm{~nm}$ and above $263 \mathrm{~nm}$; >65\% from 244 $\mathrm{nm}-256 \mathrm{~nm}$ ) and one for the $226 \mathrm{~nm}$ light (Layertec $\mathrm{GmbH}:<1 \%$ transmission at $226 \mathrm{~nm} ;>80 \%$ from $235 \mathrm{~nm}-$ $280 \mathrm{~nm}$ ), were used to block this scatter. However, it was determined that the $355 \mathrm{~nm}$ filter blocked approximately $75 \%$ of the NO fluorescence, thus drastically reducing signal levels. Therefore, a second approach, consisting of delaying the camera exposures and only using the $226 \mathrm{~nm}$ filter, was adopted to avoid this scatter and improve signal-to-noise ratio levels. The $1^{\text {st }}$ and $2^{\text {nd }}$ camera exposures were delayed by approximately $\Delta t_{P D}=28 \mathrm{~ns}$ after the start of the respective probe laser pulses (where the subscript PD means probe delay). This delay setting corresponded to a combined delay (pump and probe delay) of $\Delta t_{P U M P}+\Delta t_{P D}=35.2 \mathrm{~ns}+28 \mathrm{~ns}=63.2 \mathrm{~ns}$ beyond the start of the pump laser. While collisional quenching at the conditions of interest in this paper (static pressure, $P_{\text {static }}=$ $2900 \mathrm{~Pa}$; edge temperature, $T_{e}=240 \mathrm{~K}$ ) resulted in a relatively short NO fluorescence lifetime of approximately $30 \mathrm{~ns}$ - $40 \mathrm{~ns}$, and while delaying the camera exposures further reduced the amount of fluorescence signal, a sufficient amount of signal was collected to maintain adequate signal-to-noise levels throughout the experiment.

The second modification involved using a series of UVreflective mirrors to guide both of the probe laser beams from the laser carts to the tunnel test section rather than anti-reflection coated $90^{\circ}$ turning prisms, as were used in the previous experiment. The turning prisms used in the previous experiment were measured to transmit only $70 \%$ $90 \%$ of the incident laser energy per prism. By using $99 \%$ reflective dielectric turning mirrors, the measured laser energies for the pump, $1^{\text {st }}$ probe, and $2^{\text {nd }}$ probe at the test section prior to passing through the sheet-forming and

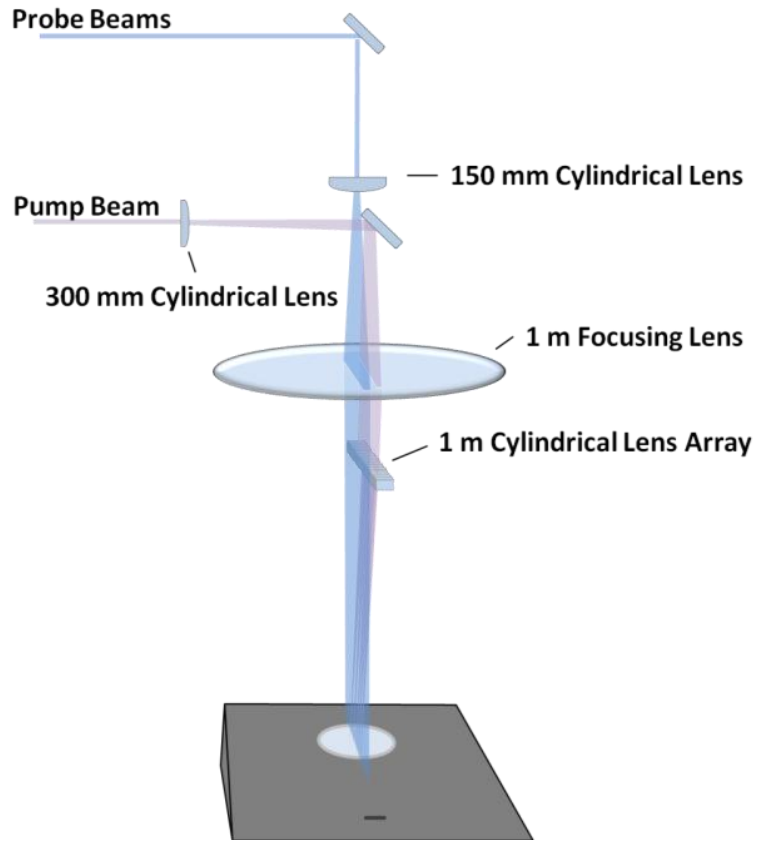

Figure 2. Schematic of alignment of pump beam and probe beams. 
profile-forming optics were approximately 10 $\mathrm{mJ} / \mathrm{pulse}, \quad 3.1 \mathrm{~mJ} / \mathrm{pulse}$, and $4.3 \mathrm{~mJ} / \mathrm{pulse}$, respectively. In the previous experiment, the approximate measured energies of the pump, $1^{\text {st }}$ probe, and $2^{\text {nd }}$ probe at this location were 11-14 $\mathrm{mJ} /$ pulse, $\quad 0.7 \mathrm{~mJ} /$ pulse, and $0.7 \mathrm{~mJ} / \mathrm{pulse}$, respectively. This represents an improvement in the transmitted $1^{\text {st }}$ and $2^{\text {nd }}$ probe laser energies by a factor of 4.4 and 6.1, respectively.

A third change involved the alignment of the pump beams formed by the cylindrical lens array relative to the model surface. Since the plate angleof-attack throughout the experiment was fixed at $20^{\circ}$, the angle of incidence was between

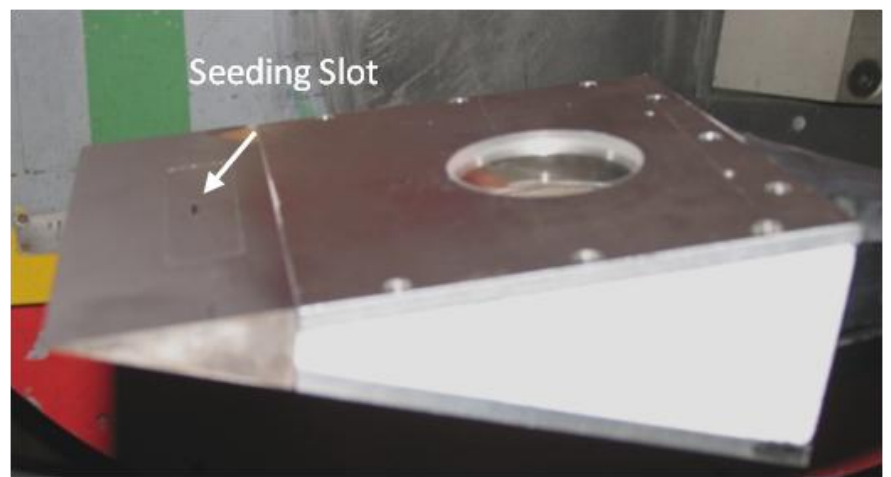

Figure 3. Wind tunnel model with quartz insert on upper (measurement) surface. approximately $3^{\circ}$ to $5^{\circ}$ with respect to the plate surface. In the previous experiment, the angle of incidence was approximately $15^{\circ}$.

Figure 2 provides a schematic detailing the optical components used to overlap the probe laser sheets with the pump beams. The view is from an upstream perspective looking downstream at the model. The exact spacing of the optics and the beam dimensions in this figure are not to scale.

Finally, the magnification of the current experiment was slightly improved by approximately $8 \%$ to 16.3 pixels $/ \mathrm{mm}$. This was accomplished by moving the camera closer to the test section. The horizontal spatial resolution ranged between approximately $0.6 \mathrm{~mm}$ (width of tagged profile) and $1.3 \mathrm{~mm}$ (maximum shift in tagged profile for $\triangle t_{P R O B E}=1 \mu \mathrm{s}$ with edge velocity of $1289 \mathrm{~m} / \mathrm{s}$ ). If a $\triangle t_{P R O B E}=2 \mu \mathrm{s}$ setting is used, the spatial resolution is reduced to $2.6 \mathrm{~mm}$. The vertical spatial resolution was approximately $0.12 \mathrm{~mm}$ (limited by pixel blooming).

\section{Wind Tunnel Model}

A thorough description of the wind tunnel model used in the current experiment - shown in Fig. 3-is provided in Refs. 5 and 6 and most recently in Ref. 13. The only modification made to the model relative to the previous experiment described in Ref. 13 was the inclusion of another quartz window, identical to the one on the upper measurement surface, on the underside surface. The leading edge of this window was positioned $95.4 \mathrm{~mm}$ downstream of the leading edge of the model. The location of this window on the lower surface of the model allowed nearly all laser light from both the pump and probe beams to pass completely through the model so that laser scatter off of internal model surfaces was minimized. This in turn lowered the noise levels imaged over the measurement surface and ultimately served to further improve signal-to-noise levels. A small portion of the incident light was observed in the experimental images reflecting off of the lower surface window and being redirected through the window on the measurement surface. A J-type thermocouple was attached to the underside of the model's 1/5 inch thick stainless steel surface with Kapton ${ }^{\circledR}$ tape to measure the plate temperature. The placement of the thermocouple provided only an estimate of the true plate temperature. The temperature measurement did not account for heat transfer effects occurring through the thickness of the plate.

For the quiescent flowfield study, care was taken to isolate the measurement region from any potential flow resulting from leaks within the tunnel facility while trying to maintain a constant static pressure. This was accomplished by placing a housing made of cardstock paper around the measurement region, affixed to the model surface. The housing had an opening on the top surface that allowed the pump and probe beams to interrogate the measurement region. Large openings on both spanwise sides of the housing were also included to allow viewing by the imaging system.

After the completion of the current experiment, it was discovered that the pressure reading for the $\mathrm{NO}_{2}$ supply plenum inside the model during the boundary layer measurements was consistently lower than that of the measured plate static pressure. Since $\mathrm{NO}_{2}$ was observed to be flowing into the boundary layer during normal operation with tunnel gases flowing, the true plenum pressure had to be greater than that of the measured static plate pressure. Thus, it was determined that a leak had formed somewhere between the $\mathrm{NO}_{2}$ plenum and the associated pressure gauge (Druck, model PDCR 4060, 0.04\% accuracy to 5 psia). The following paragraphs detail how the plumbing setup was designed to operate normally, how it was checked for leaks post test, and how this uncertainty was quantified.

The plenum itself was supplied with $\mathrm{NO}_{2}$ from both a 1 standard liter per minute (SLPM) and a 10 SLPM mass flow controller via a single 0.03 -inch diameter stainless steel tube. Absent any leaks, the gas then exited the seeding slot (identified in Fig. 3). A $L=1.37-\mathrm{m}$ long, $D=1.1-\mathrm{mm}$ inner-diameter stainless steel tube connected to the 
plenum was fed through the model sting and into the model housing box, where a T-junction split the line, with one end being connected to the Druck pressure gauge and the other end being capped off. A post-test examination of the $1.37-\mathrm{m}$ long section of pressure line revealed no leak, and it was therefore assumed that the leak most likely occurred between the end of this pressure line and the Druck gauge. It also appeared that the leak was relatively small, as the measured plenum pressure, $P_{\text {Leak }}$, was no less than $252 \mathrm{~Pa}$ of the measured plate pressure, $P_{\text {Plate, }}$, but was, on average, $2600 \mathrm{~Pa}$ above that of the measured model housing box pressure where the Druck gauge was located. However, it was unclear as to what percentage of the supplied mass flow rate was actually being fed through the seeding slot as opposed to the leak site, so an analysis was performed to quantify this error.

Since the supplied mass flow rate, static plate pressure, area of the seeding slot, pressure line inner diameter, and measured plenum pressure were all known, an estimate of the mass flow rate through both the seeding slot and leak site could be obtained by performing a simple pipe flow analysis. For the simple analysis, it was assumed that the leak site was located at the end of the plenum pressure line. Based upon analysis of previous experimental data in which no leak was present, a loss coefficient of $C_{\text {loss }}=1.75$ was estimated for the seeding slot. Three simple equations were used to describe the mass flow rate through the slot, $\dot{m}_{\text {Slot }}$, and through the pressure line, $\dot{m}_{\text {Leak }}$ :

$$
\begin{gathered}
\dot{m}_{\text {Slot }}=A_{\text {Slot }} \sqrt{\frac{2 \cdot \rho_{\text {Slot }}\left(P_{\text {Plenum }}-P_{\text {Plate }}\right)}{C_{\text {loss }}}} \\
\dot{m}_{\text {Leak }}=\frac{P_{\text {Plenum }}\left(P_{\text {Plenum }}-P_{\text {Leak }}\right) \pi D^{4}}{128 \cdot R_{N O_{2}} \cdot T_{\text {Plenum }} \cdot \mu_{\text {Plenum }} \cdot L} \\
\dot{m}_{\text {Slot }}+\dot{m}_{\text {Leak }}=\dot{m}_{\mathrm{NO}_{2}}
\end{gathered}
$$

where $A_{\text {Slot }}$ is the area of the seeding slot, $\rho_{\text {Slot }}$ is the density at the exit of the slot, $P_{\text {Plenum }}$ is the true pressure in the plenum (unknown), $P_{\text {Plate }}$ is the measured plate pressure, $P_{\text {Leak }}$ is the measured plenum pressure at the site of the leak, $R_{\mathrm{NO}_{2}}$ is the gas constant for $\mathrm{NO}_{2}, T_{\text {Plenum }}$ is the temperature of the plenum gas $(300 \mathrm{~K}), \mu_{\text {Plenum }}$ is the viscosity of the plenum gas at $T_{\text {Plenum }}$, and $\dot{m}_{\mathrm{NO}_{2}}$ is the mass flow rate of $\mathrm{NO}_{2}$ supplied to the plenum from the mass flow controllers.

From this analysis, it was determined that the flow rate through the leak was, at worst, $1 \%$ of the supplied mass flow rate, $\dot{m}_{\mathrm{NO}_{2}}$. Therefore, it is assumed that the mass flow rate supplied to the plenum was essentially the same as that issued from the seeding slot for all measurements.

\section{Experimental Conditions}

Table 1 below provides a list of both the static flow and boundary layer test conditions that are analyzed in this paper. The paper itself is broken into two results sections.

Table 1. Experimental conditions.

\begin{tabular}{cccccc}
\hline \hline Run & $\operatorname{Re}_{\infty}\left(\mathrm{m}^{-1}\right)$ & $\mathrm{P}_{\text {static }}(\mathrm{kPa})$ & $\Delta \mathrm{t}_{\mathrm{PROBE}}(\mu \mathrm{s})$ & $\dot{\mathrm{m}}_{\text {Blowing }}(\mathrm{mg} / \mathrm{s})$ & Test Objective \\
\hline 18 & 0 & 2.89 & 1 & 30.2 & \\
17 & 0 & 2.89 & 2 & 30.5 & Spatial uncertainty, data yield, accuracy, signal-to-noise \\
19 & 0 & 2.89 & 5 & 30.0 & \\
20 & 0 & 2.89 & 10 & 30.5 & \\
21 & 0 & 2.89 & 25 & 30.6 & \\
26 & 0 & 0.41 & 2 & 30.8 & \\
25 & 0 & 0.59 & 2 & 30.8 & \\
24 & 0 & 1.29 & 2 & 30.6 & \\
23 & 0 & 2.61 & 2 & 30.3 & \\
27 & 0 & 6.80 & 2 & 30.8 & Velocity measurement repeatability, uncertainty \\
28 & 0 & 13.70 & 2 & 31.0 & \\
29 & 0 & 27.53 & 2 & 30.8 & Velocity perturbation, instability, optimal blowing rate \\
5 & $3.2 \times 10^{6}$ & 2.77 & $1,2,5$ & $15.6,15.6,8.8$ & \\
12 & $3.2 \times 10^{6}$ & 2.77 & 2 & $15.3-161.3$ & \\
\hline \hline
\end{tabular}

The first results section consists of two subsections (the first two sections in Table 1) which detail measurements in a relatively quiescent flowfield for which: (1) the probe laser delay was varied and static pressure was held constant and (2) the probe laser delay was held constant and static pressure was varied. The analysis methods used to process the data in these sections is identical to that used in Ref. 13 and so will not be detailed in this paper. 
Rather, the updated results which incorporate the experimental improvements discussed in II.B and II.C will be presented.

The remaining results section will detail two boundary layer velocity measurements (the latter two sections in Table 1) for which: (1) the probe laser delay was varied and blowing rate held constant and (2) probe laser delay was held constant and blowing rate was varied.

\section{Quiescent Flow Calibration Results}

A. Quiescent Flow: Variable $\Delta \mathbf{t}_{\text {PRoBE }}$, Constant $\mathbf{P}_{\text {static }}$

Figure 4 shows the spatial component of the uncertainty in velocity, or spatial uncertainty, $u_{U, \Delta x}$, defined as:

$$
u_{U, \Delta x}=\sigma_{U, \Delta x} \cdot t_{v, 95 \%}
$$

where $\sigma_{U, \Delta x}$ is the standard deviation of velocity for all of the single-shot measurements and $t_{v, 95 \%}$ is the Student tstatistic at $95 \%$ confidence. This value is plotted as a function of the signal-to-noise ratio (SNR). This spatial uncertainty is composed of uncertainties in determining the displacement, $\Delta x$, of the tagged profiles, which in turn are attributable to: 1) flow unsteadiness resulting in measured fluctuations in $\Delta x$ and 2) reduced signal-to-noise levels resulting in errors in determining the precise value of $\Delta x$ due to poorly conditioned crosscorrelation results. This uncertainty is the largest contributor to the total velocity uncertainty. The inset plot in Fig. 4 represents the spatial uncertainty at $95 \%$ confidence in terms of measured displacement of the velocity profiles in units of pixels. In both of these plots, the spatial uncertainty is computed from velocity data binned together according to signal-to-noise ratio, incremented by 0.25 . For this analysis, if fewer than 100 singleshot measurements were used to compute a particular $u_{U, \Delta x}$ value, the point was

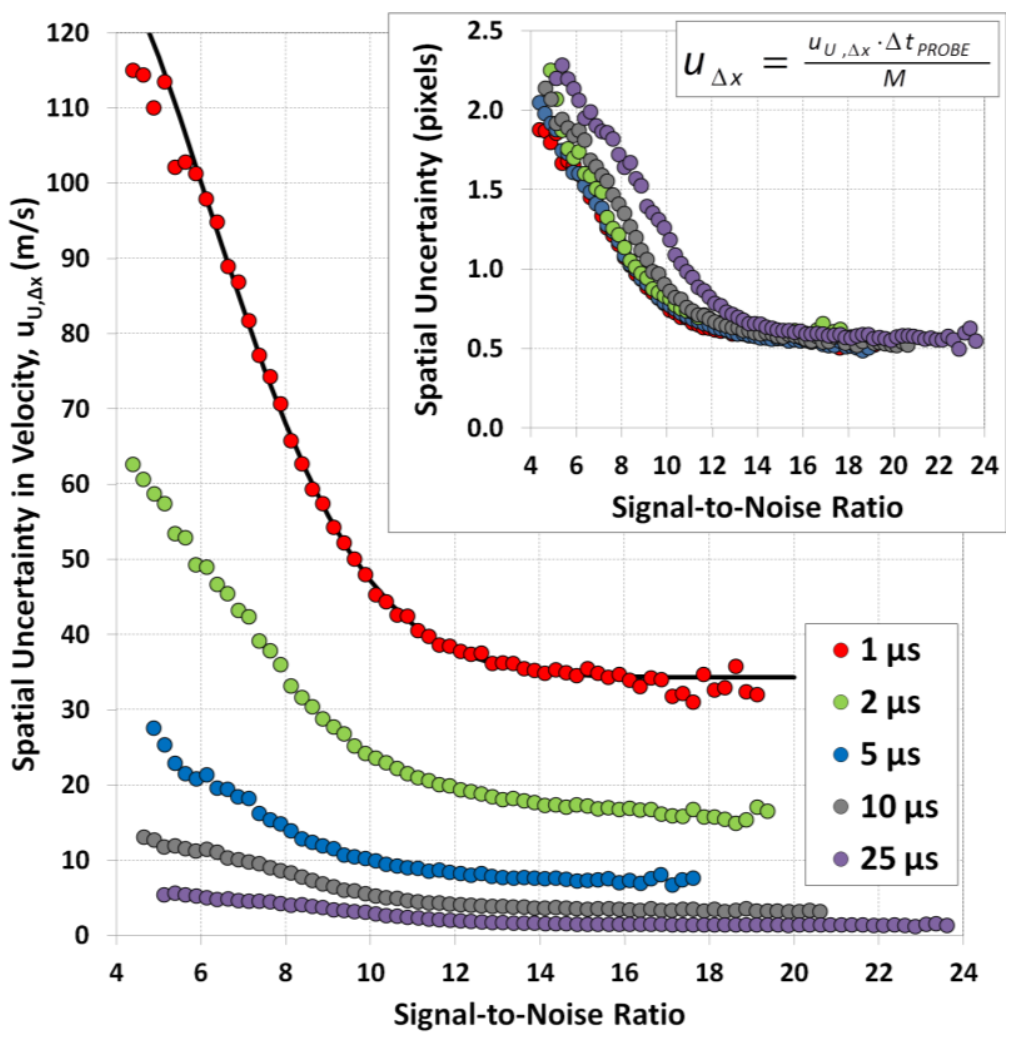

Figure 4. Measured spatial uncertainty in velocity (larger plot) and pixels (inset plot) as a function of signal-to-noise ratio for several $\Delta t_{P R O B E}$ settings. $P_{\text {static }}=$ rejected. The gain setting of the DiCAM- $2.9 \mathrm{kPa}$.

Pro camera for this study was $20 \%$. The gain setting in the previous study (Ref. 13) was $60 \%$.

Two significant differences are observed when comparing the spatial uncertainty in velocity results (larger plot in Fig. 4) with the previous results in Fig. 4 of Ref. 13. First, the spatial uncertainty has been reduced by approximately a factor of 2 overall. Second, the behavior of spatial uncertainty as a function of signal-to-noise ratio in this paper's Fig. 4 is similar to that of the right-hand-side of a Gaussian-like distribution given by:

$$
u_{U, \Delta x}=\frac{A+B \exp [-C(S N R-\mu)](-C)}{\Delta t_{P R O B E}}
$$

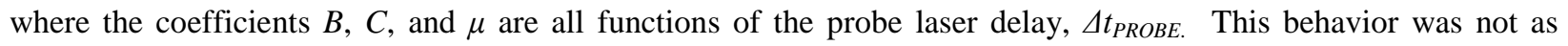
apparent in Fig. 4 of Ref. 13. However, inspection of those previous data shows that signal-to-noise ratiosespecially for shorter $\triangle t_{P R O B E}$ settings-were generally 12.5 or less. When compared to the current data, it may be that the extent of the trends observed in the previous data set could have been represented by the linear portion of the right-hand-side of a Gaussian-like distribution, but the wings of such a distribution could not be resolved because of limited signal-to-noise ratios. In both the current and previous data sets, the approximate slopes of the linear portion 
of spatial uncertainty are of the same order of magnitude (-12.2 and -16.2, respectively). For the velocity measurements presented in this paper, only measurements with signal-to-noise values of 5 or greater are accepted for processing.

Examination of the inset plot in Fig. 4 also shows two important trends. First, considering the data at the highest signal-to-noise levels, the current image analysis method can measure velocity to within 0.5 pixels at $95 \%$ confidence. This limit appears to be nearly independent of $\triangle t_{P R O B E}$ for the conditions of this experiment and could be the result of a systematic error in the image analysis algorithm, a true velocity fluctuation in the flowfield, or both. Second, when $\triangle t_{P R O B E}$ is increased, the uncertainties at lower signal-to-noise levels are higher. This behavior is probably caused by mass diffusion which increases the width of the line of excited molecules, broadening the correlation peak and making it more difficult to identify the center of the peak.

Figure 5 shows the data yield as a function of signal-to-noise ratio for the five $\triangle t_{P R O B E}$ settings tested. The data yield is defined as the percent of measurement points that resulted in a valid velocity measurement after applying the rejection threshold. At the lowest signal-to-noise levels (SNR < 5.5), the data yield trend is nearly the same for each $\Delta t_{P R O B E}$. At the highest SNR levels (SNR > 14), the data yield is nearly $100 \%$ for each probe delay. This is an improvement over the previous data set (Ref. 13), in which the highest yields achieved were approximately $90 \%$. Also of significance is the reduction in scatter of the data yield trends relative to Fig. 5 in Ref. 13.

For signal-to-noise levels between 5.5 and 14, the slope of transition region (the region in which the data yield changes from less than $10 \%$ to nearly $100 \%$ ) decreases with increasing probe delay. Again, this may be a result of gas diffusion adversely affecting data yield in this region.

Figure 6 shows the computed

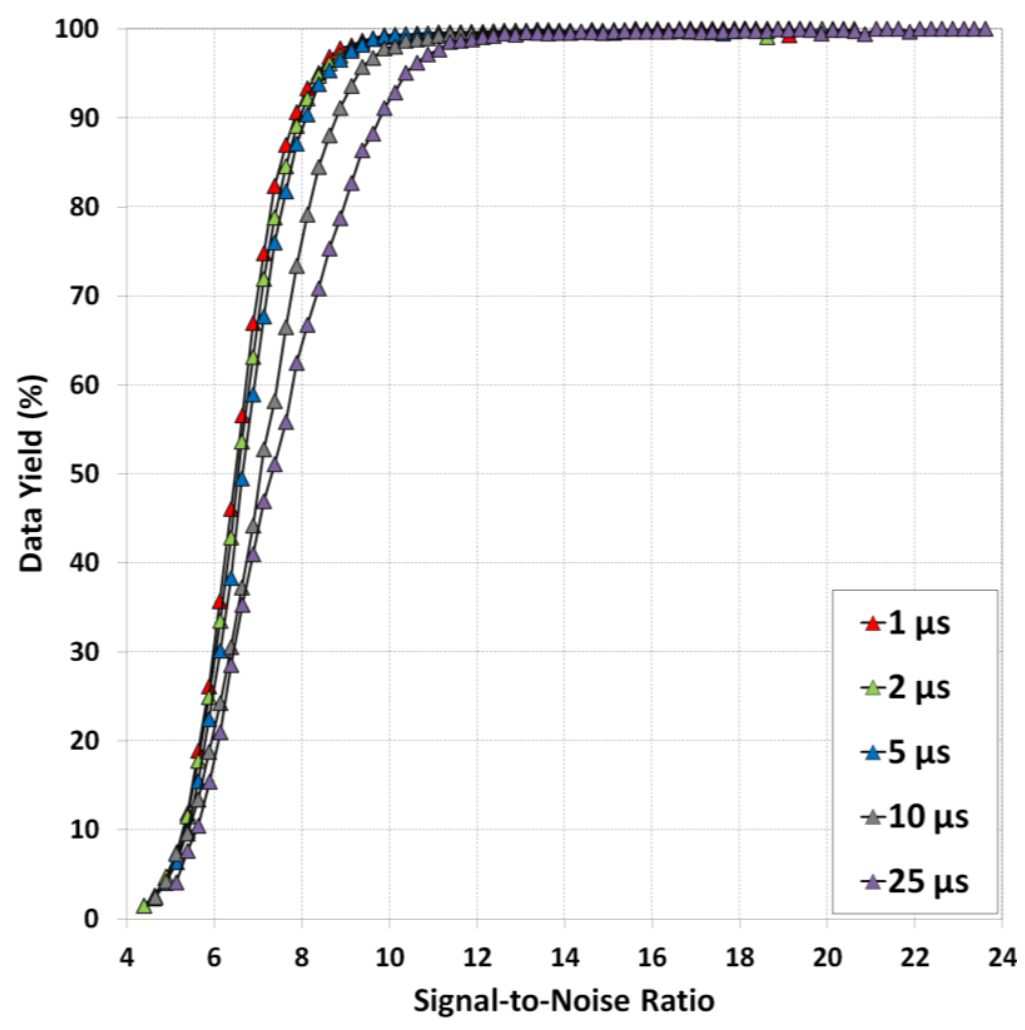

Figure 5. Data yield as a function of signal-to-noise ratio for several $\triangle t_{P R O B E}$ settings.

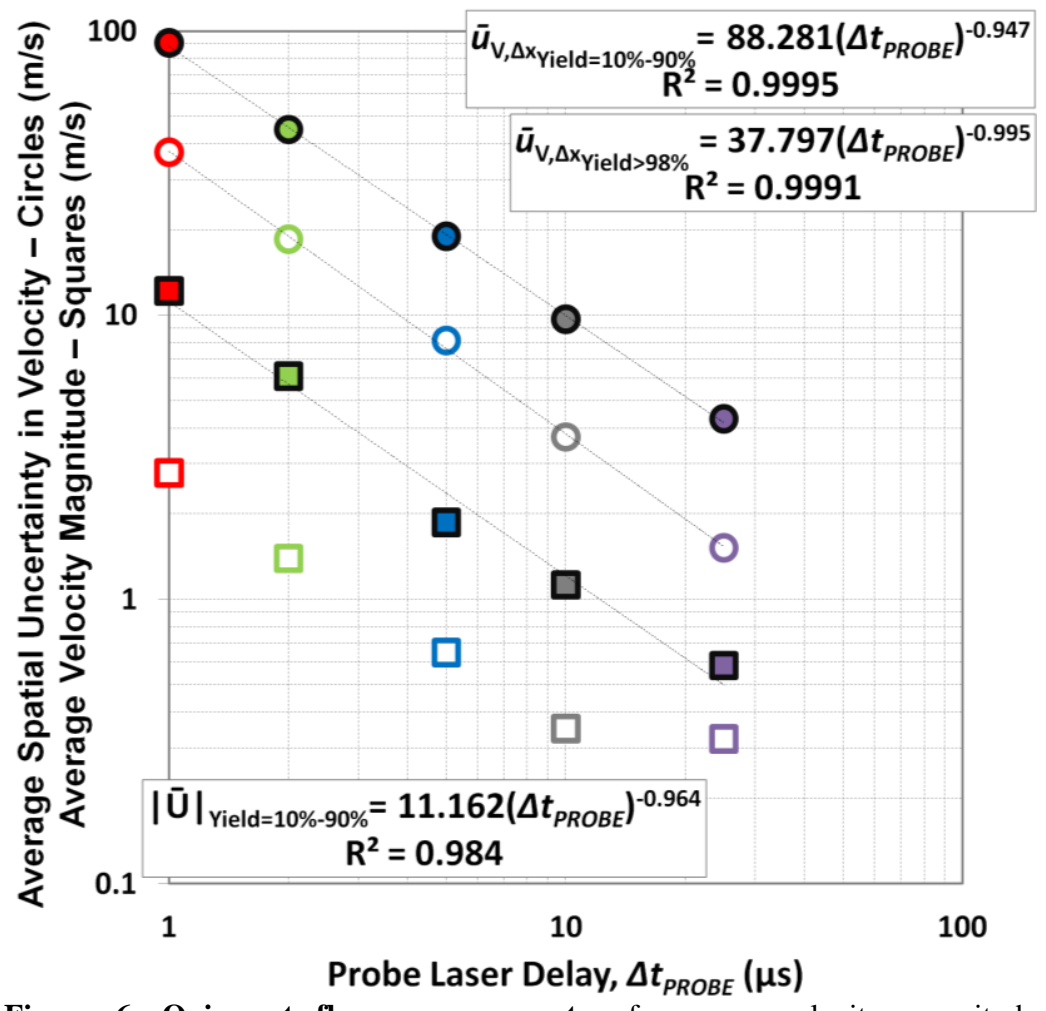

Figure 6. Quiescent flow measurements of average velocity magnitude (squares) and the associated average spatial uncertainty in velocity (circles) for high (open) and lesser (filled) data yields as functions of $\triangle t_{P R O B E} . \quad P_{\text {static }}=2.9$ $\mathrm{kPa}$. 
average of spatial uncertainty (circle data points) as a function of $\Delta t_{P R O B E}$ setting, rather than signal-to-noise ratio, as in Fig. 4. This average is first computed for all data with a yield between 10\%-90\% (solid circle data points), corresponding to both the transition region shown in Fig. 5 and the linear portion of the Gaussian-like distribution in Fig. 4. The average is also computed for all data with a yield above 98\% (empty circle data points), which corresponds to the wing of the Gaussian-like distribution in Fig. 4. These points represent the "best case" spatial uncertainty behavior for the current experiment. In both instances, the average uncertainty decreases monotonically with $\triangle t_{P R O B E}$ and it follows the power fit relation provided in the upper right-hand corner of the plot.

Figure 6 also shows measured mean velocity magnitude as a function of the time between the two probe pulses, $\triangle t_{P R O B E}$, represented by the square data points. For the velocity data with a yield between $10 \%-90 \%$ (solid square data points), the same monotonically decreasing pattern as observed in spatial uncertainty occurs. This data follows the power fit shown in the bottom left-hand corner of the plot. The velocity data with a yield greater than $98 \%$ (empty square data points) exhibits a similar trend up to $\Delta t_{P R O B E}=10 \mu \mathrm{s}$. However, for $\Delta t_{P R O B E}=25 \mu \mathrm{s}$, no further reduction in average velocity magnitude occurs. This suggests that the nearly quiescent flow actually had small fluctuations in velocity of about $0.3 \mathrm{~m} / \mathrm{s}$ and that any measured velocities above this level are due to systematic errors in the measurement system. The average velocity magnitudes denoted by filled square symbols in Fig. 6 represent the accuracy term, $u_{\text {Accuracy }}$, used in the calculation of both uncertainty in mean velocity and single-shot velocity.

For the average velocity magnitude trend shown in Fig. 5 , the dependence of these values on $\Delta t_{P R O B E}$ to a particular power is similar to the behavior given by the relations:

$$
\overline{|U|}=\frac{\Delta x_{\text {true }}+\Delta x_{\text {systematic error }}}{\Delta t_{P R O B E}}
$$

where $\Delta x_{\text {true }}$ is the true displacement of the gas in an amount of time, $\Delta t_{P R O B E}$, and $\Delta x_{\text {systematic error }}$ is a systematic error of constant magnitude associated with the analysis method. For small $\Delta t_{P R O B E}$ settings, the magnitude of $\Delta x_{\text {systematic }}$ error may be significant compared to $\triangle x_{\text {true }}$ and therefore have a significant effect on measured velocity. As $\triangle t_{P R O B E}$ is increased, the influence of $\Delta x_{\text {systematic error }}$ on measured velocity is diminished. The trends in Fig. 6 therefore provide a quantitative description of the contribution of the spatial uncertainty to the systematic error present in the measurement.

\section{B. Quiescent Flow: Constant $\Delta t_{P R O B E}$, Variable $\boldsymbol{P}_{\text {static }}$}

Figure 7 shows how the average spatial uncertainty in velocity, average signal-to-noise ratio, and average velocity magnitude behave as functions of static pressure. Each data point in Fig. 7 was computed by averaging only data having the highest $10 \%$ of signal-to-noise ratio values for any particular static pressure condition. The gain setting of the DiCAM-Pro camera for this study was $40 \%$, with the exception of the unshaded data points in Fig. 7, for which the gain setting was $20 \%$. The gain setting in the previous study (Ref. 13) was $60 \%$.

The average spatial uncertainty in velocity, denoted by the circular data points, reaches a minimum at $6.8 \mathrm{kPa}$. Both the trend and location of the minimum are nearly identical to the result obtained in Ref. 13, however the

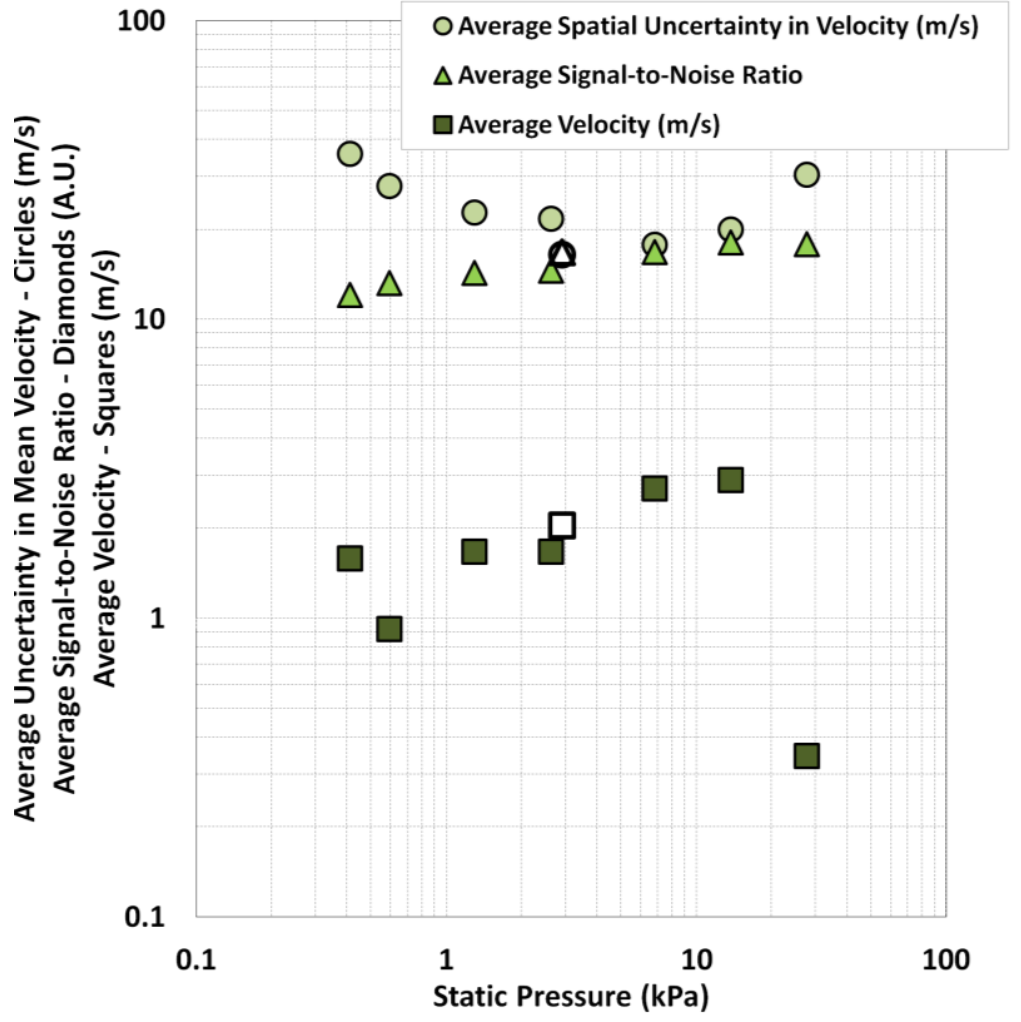

Figure 7. Behavior of average spatial uncertainty (circular data points), average signal-to-noise ratio (diamond data points), and average velocity (square data points) as functions of $P_{\text {static }}$. Measurements were obtained with $\Delta t_{P R O B E}=2 \mu \mathrm{s}$ and $40 \%$ camera gain except unshaded symbols, which were obtained with $20 \%$ camera gain. 
magnitude at this minimum is approximately 3.8 times lower than that observed in the previous work. Half of this improvement is caused by the increased $\triangle t_{P R O B E}$ setting used in this experiment $(2 \mu \mathrm{s})$ compared to the previous work $(1 \mu \mathrm{s})$. The average signal-to-noise ratio data, denoted by the diamond data points, generally increases with pressure reaching a maximum at nearly the highest pressure studied $(13.7 \mathrm{kPa})$. Improved signal to noise ratio probably accounted for most of the rest of the improvement in precision (reduction in spatial uncertainty in velocity) compared to the past experiment.

The average velocity magnitude provides a measure of the accuracy of the measurement system (the true flow velocity was determined from Fig. 6 to on the order of $0.3 \mathrm{~m} / \mathrm{s}$ ). The average velocity magnitude is denoted by the square data points, is observed to scatter in the range of $0.3 \mathrm{~m} / \mathrm{s}-3 \mathrm{~m} / \mathrm{s}$. The behavior of the average velocity measured in a quiescent flow stands in contrast to the previous data set, where the average velocity magnitude increased linearly with increasing static pressure and was nearly a factor of 10 greater than that of the current experiment. This result is partially attributable to both the increased $\triangle t_{P R O B E}$ setting and the higher signal-to-noise of this experiment.

At $27.5 \mathrm{kPa}$, the anomalous behavior of the uncertainty (increasing), signal-to-noise ratio (slightly decreasing), and velocity (decreasing), may be attributed to a relatively high level of uniform background signal observed in the images. This background was also observed, albeit to a lesser extent, in the images corresponding to $P_{\text {static }}=13.7$ $\mathrm{kPa}$. The presence of this background signal at higher values of $P_{\text {static }}$ may be the result of stagnant NO that is either present in trace amounts in the $\mathrm{NO}_{2}$ supply or it may have been generated via photolysis of the $\mathrm{NO}_{2}$.

The unshaded symbols in Fig. 7 correspond to a gain setting of $20 \%$ versus the $40 \%$ gain setting at which all other data was acquired. With this lower gain setting, a small but noticeable reduction in spatial uncertainty occurs. The signal-to-noise ratio and average velocity magnitude with a $20 \%$ gain setting also increase slightly beyond the baseline trend taken with a $40 \%$ gain setting. This possibly explains another reason for the improved precision in the current experiment compared to Ref. 13, which used a gain setting of $60 \%$.

\section{Hypersonic Boundary Layer Measurement Results}

\section{A. Velocity Measurement in the Hypersonic Boundary Layer: Variable $\Delta t_{P R O B E}$, Constant $\dot{m}_{\text {Blowing }}$}

Figure 8 shows several mean velocity profiles acquired at multiple streamwise locations with two $(1 \mu \mathrm{s}-$ red data points, $2 \mu \mathrm{s}$ - green data points) of the three probe laser delay settings, $\triangle t_{P R O B E}$. The horizontal axes correspond to streamwise velocity magnitude and the vertical axes correspond to wall-normal position away from the model surface. The widths of the bars correspond to the uncertainty in the mean velocity. Only data for which the percentage of points used to compute the mean and uncertainty values was greater than or equal to $10 \%$ of the total number of images in the set are presented in this figure. The gain setting of the DiCAM-Pro camera for this study was $20 \%$.

Over the course of a wind tunnel run, a small physical displacement of the model was observed, presumably a result of non-uniform thermal loading of the sting. It is estimated that during the $\Delta t_{P R O B E}=1 \mu \mathrm{s}$ and $\Delta t_{P R O B E}=2 \mu \mathrm{s}$ acquisition periods, the model was displaced downward (that is, into the model surface) by $0.6 \mathrm{~mm}$ and $0.3 \mathrm{~mm}$, respectively. This estimate was based on analysis of laser scatter off of the model surface both immediately upstream and downstream of the quartz window insert. To correct for this displacement, the single-shot images were shifted vertically based on a $2^{\text {nd }}$-order polynomial fit of the scatter data such that the model surface appeared stationary in all of the images in the set. The heights of the bars in Fig. 8 roughly convey the uncertainty in vertical position of the data after the correction, but do not represent a quantitative estimate of this uncertainty. This displacement could also have altered the plate angle-of-attack, however this effect has not yet been quantified.

For both data sets presented in Fig. 8, the mean blowing rates were $\dot{m}_{\text {Blowing }}=15.6 \mathrm{mg} / \mathrm{s}(0.501$ standard liters per minute, SLPM). The average plate temperature (measured with a thermocouple mounted to the back side of the top surface of the model) for the $\Delta t_{P R O B E}=1 \mu \mathrm{s}$ data was $315 \mathrm{~K}$, and for the $\Delta t_{P R O B E}=2 \mu \mathrm{s}$ data was $372 \mathrm{~K}$. During the $\Delta t_{P R O B E}=1 \mu \mathrm{s}$ acquisition period, either the pump laser beams, probe laser sheets, or both were noticeably shifting relative to each other and relative to the model. This reduced the total number of images available for analysis in that particular data set. The pump and probe laser energies were also not uniform over the measurement region during this experiment. As a result, the laser intensity distribution in both upstream and downstream directions away from the profile located at $100.5 \mathrm{~mm}$ from the leading edge was visibly diminished. This limited the measurement region to profiles located between $98.4 \mathrm{~mm}$ and $108.2 \mathrm{~mm}$ downstream of the leading edge.

Data were also acquired for a $\triangle t_{P R O B E}=5 \mu \mathrm{s}$ setting. However, the combination of a relatively low blowing rate ( $\dot{m}_{\text {Blowing }}=8.8 \mathrm{mg} / \mathrm{s}, 0.283 \mathrm{SLPM}$ ), relatively low signal-to-noise levels, and the inability of the analysis algorithm to distinguish between successive streamwise profiles did not allow for analysis of this data set. Figure 9 provides an averaged image from each $\triangle t_{P R O B E}$ data set. This figure highlights the relatively poor quality of the $\Delta t_{P R O B E}=5 \mu \mathrm{s}$ 
data relative to the $1 \mu$ s and $2 \mu$ s data. Measurements with the $5 \mu$ s delay might have been possible if alternating lenses on the cylindrical lens array were blocked.

In Fig. 8, the data between approximately $0.05 \mathrm{~mm}$ and $0.60 \mathrm{~mm}$ above the model surface agree relatively well with analytic solutions corresponding to each acquisition period (both $\triangle t_{P R O B E}=1 \mu \mathrm{s}$ and $\Delta t_{P R O B E}=2 \mu \mathrm{s}$ ). While the data sets do not overlap entirely in this region-which is most likely a result of differing wall temperatures affecting the velocity profiles - the measurements obtained in this region demonstrate two important aspects of the technique. First, the measurement technique is repeatable and nearly independent of the $\Delta t_{P R O B E}$. The exception to this being a $\triangle t_{P R O B E}$ setting that is too great (i.e. $5 \mu \mathrm{s}$ ), in which case the individual profiles cannot be adequately resolved. Second, a small but noticeable reduction in the uncertainty in the mean velocity accompanies an increased $\Delta t_{P R O B E}$ setting. For the region between $0.05 \mathrm{~mm}$ and $0.60 \mathrm{~mm}$, the average reduction in the uncertainty in mean velocity was $10 \%$ across the streamwise profile $102.4 \mathrm{~mm}$ downstream of the leading edge.

For the near-wall region below $0.05 \mathrm{~mm}$, the velocity profiles do not tend linearly towards zero as expected (noslip velocity wall condition). Instead, the measured mean velocities near the wall are approximately $10 \%$ of the estimated freestream value. Figure 10 shows a single-shot pair of signal distributions from a sequential image pair (frame 174 of that set). These signal distributions are taken just above the model surface from a profile centered $102.4 \mathrm{~mm}$ downstream of the leading edge. The delayed image shows a clearly observed shift relative to the zero delay image.

At the wall, it is expected that a near-zero velocity will occur as a result of the no-slip boundary condition. However, Fig. 10 clearly shows that a shift of approximately 4 pixels is observed with a $2 \mu$ s delay, corresponding to a velocity of approximately $120 \mathrm{~m} / \mathrm{s}$, occurs at this location. Similar image pairs for the $1 \mu$ s delay would show a shift of approximately 2 pixels, corresponding to the same approximate velocity. There are several potential explanations for this behavior. First, there could, in fact, be some slip velocity at the wall, although this velocity slip is estimated to be less than $5 \mathrm{~m} / \mathrm{s}$ based on the simple equations taken from Refs. 1 and 15 :

$$
\begin{gathered}
U_{\text {slip }}=\lambda \frac{d U}{d Y} \\
\lambda=\frac{k T_{\text {wall }}}{\sqrt{2} \pi \sigma^{2} n}
\end{gathered}
$$

where $U_{\text {slip }}$ is the slip velocity, $\lambda$ is the mean-free-path, $Y$ is the spatial variable in the wall-normal direction, $k$ is Boltzmann's constant, $T$ is the wall temperature, $\sigma$ is the collisional cross-section, and $n$ is the number density.

Second, a potentially high flux of photoelectrons incident onto the camera's phosphor screen, generated by the zero delay probe beam and scatter off of the quartz surface, may have depleted the phosphor at this particular location. This would result in diminished signal at this location in the delayed image. Third, pixel blooming may be occurring as a result of relatively high signal levels imaged at this particular location. At the point where the profile is incident on the quartz window surface, blooming would bias the measured velocity via signal contamination from regions slightly above the plate surface and from reflections off of the quartz window surface. Further study is needed to determine the precise cause of this discrepancy between the measured velocity and the analytic solution.

Above $0.6 \mathrm{~mm}$, the mean velocity profiles are biased away from the analytic solution, with smaller than expected velocities relative to the analytic solutions. Potential reasons for these discrepancies include: (1) the estimated edge conditions may not reflect the true edge properties, and therefore the analytic solutions may not be representative of the true velocity layer behavior; (2) the gas seeding may alter the velocity profile, especially above $0.6 \mathrm{~mm}$, resulting in slower gas in this region; (3) any significant discrepancies existing between the velocity boundary layer thickness and the concentration boundary layer thickness that may affect the measured velocity profiles. Analysis of the single-shot images from both acquisition periods $(1 \mu \mathrm{s}$ and $2 \mu \mathrm{s})$ indicates that the profiles were, to a limited extent, oscillating irregularly in the wall-normal direction. In some instances, the tips of the profiles in the delayed images are observed bending sharply upward. However, it is not clear if this bending corresponds to a thickening of the concentration layer, thus providing an intermittent measure of the edge of the velocity layer, or if this was some form of velocity instability. A numerical study of boundary layer behavior for relatively low blowing rates ( $\leq 3 \mathrm{mg} / \mathrm{s})$ performed in Ref. 16, discussed several aspects of blowing that may be used to expand on this last potential effect. 


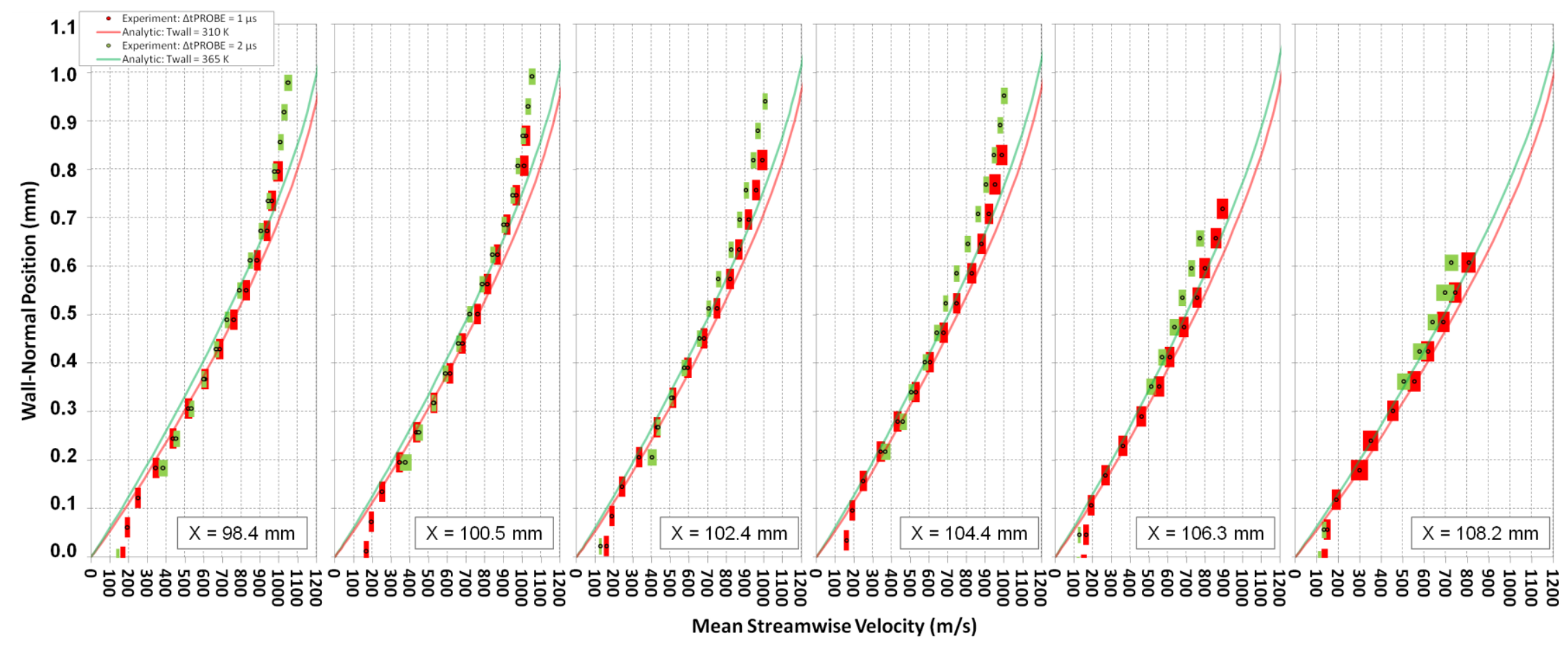

Figure 8. Mean velocity profiles for $\triangle t_{P R O B E}$ settings of $1 \mu$ s (red data points) and $2 \mu$ s (green data points). Solid red and green lines correspond to analytic velocity boundary layer solutions for wall temperatures of $310 \mathrm{~K}$ and $365 \mathrm{~K}$, respectively.

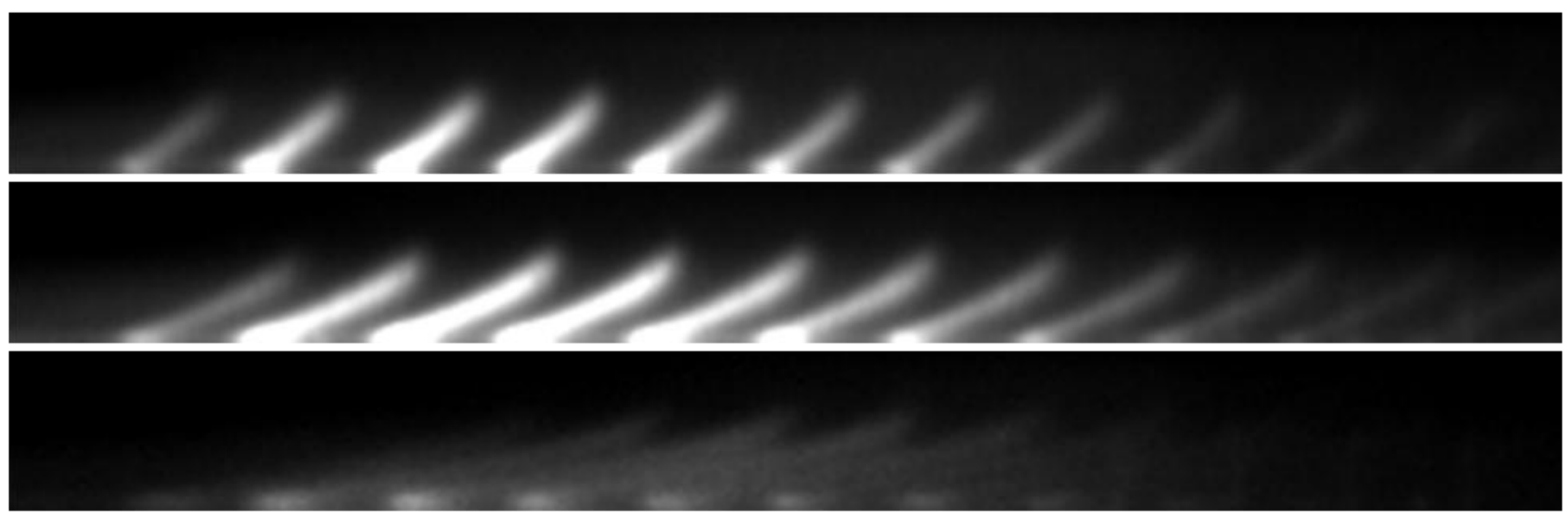

$$
\begin{aligned}
& \Delta t_{P R O B E}=1 \mu \mathrm{s} \\
& \Delta t_{P R O B E}=2 \mu \mathrm{s} \\
& \Delta t_{P R O B E}=5 \mu \mathrm{s}
\end{aligned}
$$

Figure 9. Average of raw images with $\triangle t_{P R O B E}$ settings of $1 \mu \mathrm{s}$ (top), $2 \mu \mathrm{s}$ (middle), and $5 \mu \mathrm{s}$ (bottom).

11

American Institute of Aeronautics and Astronautics 
Using the incompressible concentration layer relation provided in Eq. 1 of Ref. 16, the estimated ratio of concentration boundary layer thickness to velocity boundary layer thickness for the conditions of this experiment is approximately 0.82 . This gives a concentration layer thickness of approximately $1.04 \mathrm{~mm}$ for the profile located $102.4 \mathrm{~mm}$ downstream of the leading edge. Considering all data at this location, even those which fall below the $10 \%$ rejection criteria, the farthest measurement from the wall surface at this location was obtained at $1.12 \mathrm{~mm}$, which is within $8 \%$ of the estimated value. When the boundary layer is thicker than average, the result is a lower-than-expected measured streamwise velocity for any given vertical location. (For example, at a location that is typically just inside the freestream, a thicker-than-average boundary layer would mean slower gas at this location.) This is especially true in the upper-middle region of the profile (i.e. the thickness of the concentration layer), which is both away from the no-slip boundary

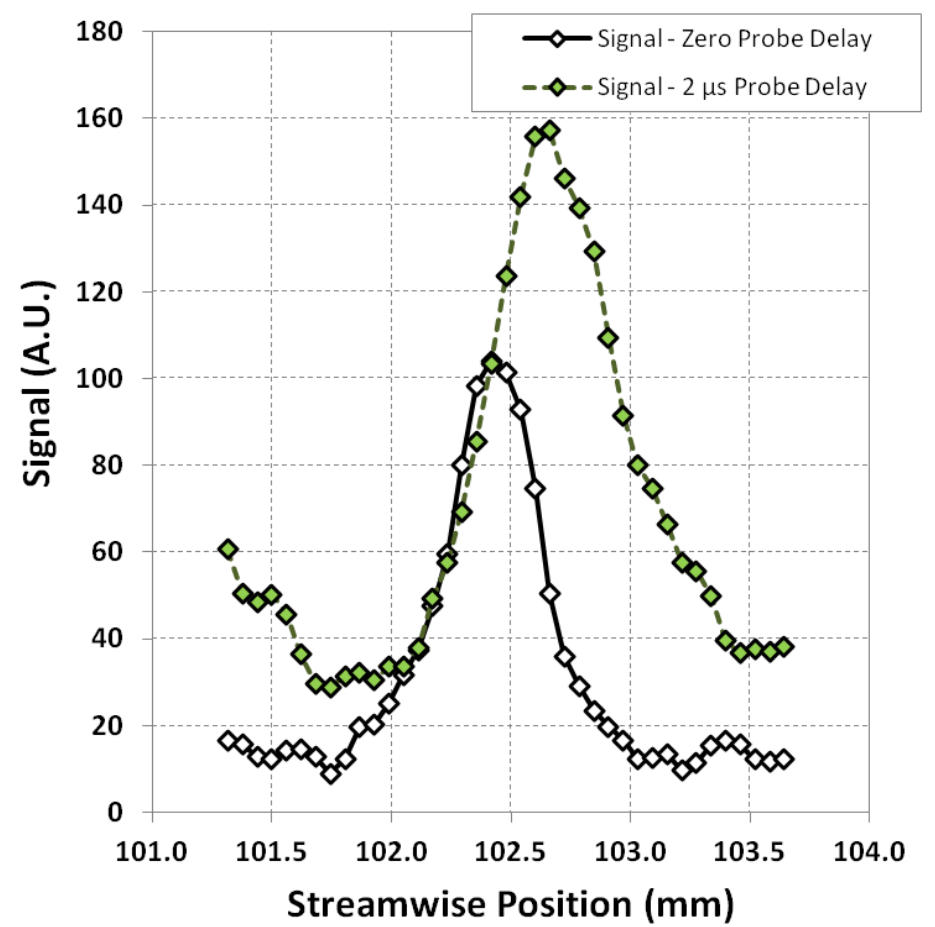

Figure 10. Single-shot signal intensity distributions at the wall for a profile located $102.4 \mathrm{~mm}$ downstream of the leading edge. condition and edge velocity boundary condition. On the other hand, when the boundary layer is thinner than average, unseeded freestream flow replaces the seeded boundary layer gas, and consequently no measurement is obtained at vertical locations near the average edge of the boundary layer. The net result of this process would be a lower-than-predicted (compared to the analytic solution) mean velocity measurement with increasing distance from the wall. Future comparisons with unsteady CFD solutions could take this biasing effect into account.

\section{B. Velocity Measurement in a Hypersonic Boundary Layer: Constant $\Delta t_{P R O B E}$, Variable $\dot{\boldsymbol{m}}_{\text {Blowing }}$}

Figure 12 shows several mean velocity profiles for $\dot{m}_{\text {Blowing }}=15.3 \mathrm{mg} / \mathrm{s}(0.491 \mathrm{SLPM}$, gray data points $)$ and $\dot{m}_{\text {Blowing }}=161.3 \mathrm{mg} / \mathrm{s}$ mass $\left(5.179 \mathrm{SLPM}\right.$, black data points). The probe delay for these data was $\Delta t_{P R O B E}=1 \mu \mathrm{s}$. These were the lowest and highest mass flow rates tested for this particular experiment. The plots are organized from left to right according to increasing streamwise position. For these acquisition periods, the measured mean wall temperatures corresponding to the $15.3 \mathrm{mg} / \mathrm{s}$ and $161.3 \mathrm{mg} / \mathrm{s}$ blowing rates were $316.8 \mathrm{~K}$ and $402.7 \mathrm{~K}$, respectively. As a reference, three analytic compressible velocity boundary layer solutions are superimposed on top of the data. The blue, green, and red profiles correspond to wall temperatures of $310 \mathrm{~K}, 365 \mathrm{~K}$, and $420 \mathrm{~K}$, respectively, which were approximately the lowest, mean, and highest wall temperatures measured over the course of the run. The inset plots in the upper left-hand corner of the velocity plots provide an estimate of the fluctuating component of streamwise velocity, $U^{\prime}$, for each blowing rate tested. These $U^{\prime}$ values are computed using Eq. 6 from Ref. 17. In each case, the instrument error, determined from Fig. 5 was subtracted in quadrature as described in Ref. 17. Thus, the $U^{\prime}$ values indicated are a measure of the fluctuations in the flow.

In Fig. 12, as in Fig. 8, the data for $\dot{m}_{\text {Blowing }}=15.3 \mathrm{mg} / \mathrm{s}$ between $0.05 \mathrm{~mm}$ and $0.60 \mathrm{~mm}$ away from the measurement surface line up relatively well with the $310 \mathrm{~K}$ analytic solution. For the $\dot{m}_{\text {Blowing }}=161.3 \mathrm{mg} / \mathrm{s}$ data, as distance downstream from the leading edge is increased, the measured mean velocity profiles demonstrate a noticeable deficit away from the analytic solution corresponding to a wall temperature of $420 \mathrm{~K}$. A higher wall temperature, which in turn would produce a thicker velocity layer profile could account for some of this discrepancy.

Considering the $U^{\prime}$ inset plots in Fig. 12, at the lower blowing rates the profiles are parabolic-like at some streamwise locations and scattered at others. This is opposed to the higher blowing rate profiles, which have a definite parabolic-like shape at each streamwise position. Generally, for the lower blowing rate profiles, the $U$, magnitudes are less than that of the higher blowing rate profiles. That is, higher blowing rates have a greater perturbative effect on the boundary layer, resulting in fluctuations that are larger in magnitude and that penetrate higher up into the boundary layer. 

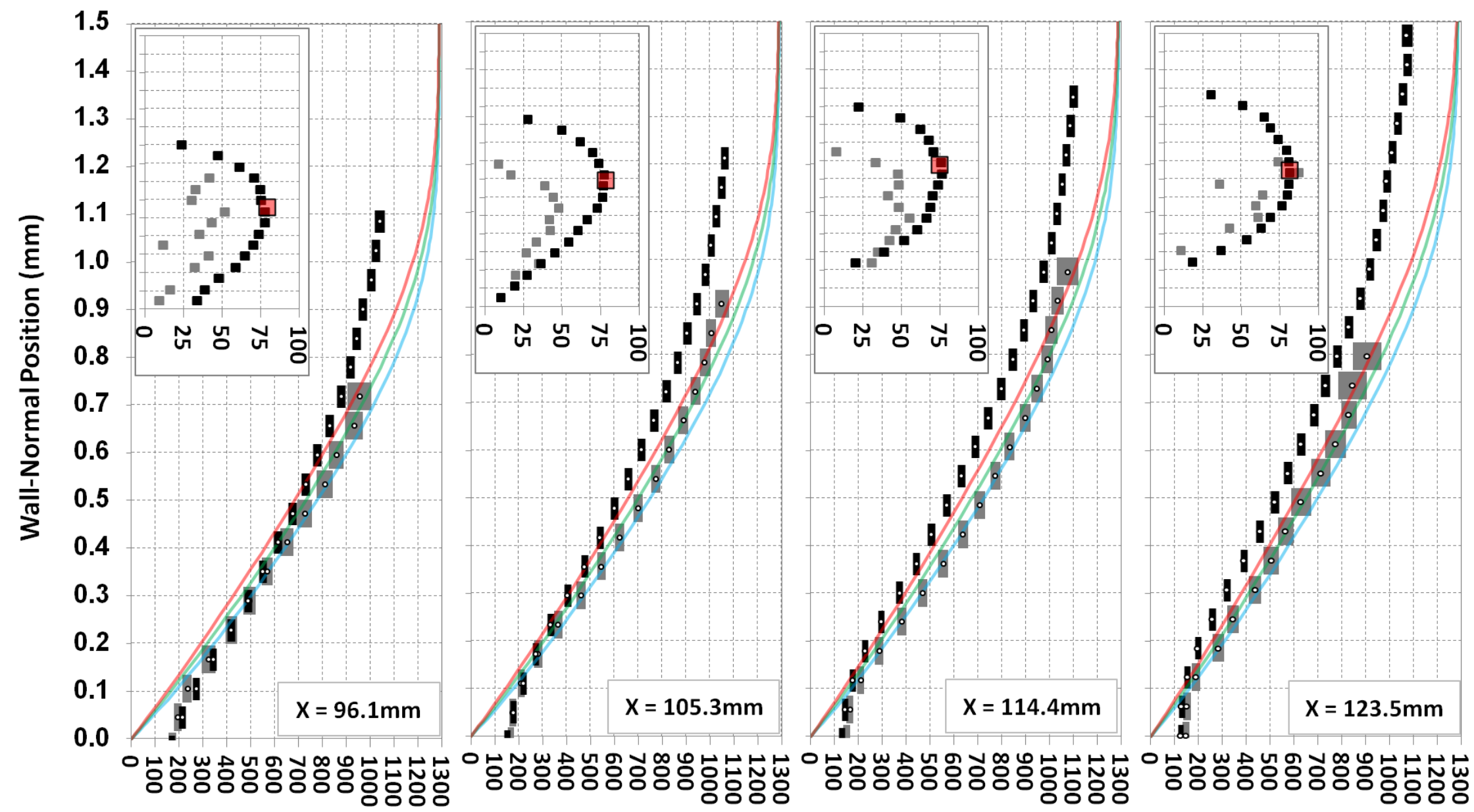

\section{Mean Streamwise Velocity $(\mathrm{m} / \mathrm{s})$}

Figure 12. Mean streamwise velocity profiles for blowing rates of $\dot{m}_{\text {Blowing }}=15.3 \mathrm{mg} / \mathrm{s}$ (gray data points) and $\dot{m}_{\text {Blowing }}=161.3 \mathrm{mg} / \mathrm{s}$ mass (black data points). Solid blue, green, and red lines correspond to analytic boundary layer solutions for wall temperatures of $310 \mathrm{~K}, 365 \mathrm{~K}$, and $420 \mathrm{~K}$, respectively. Inset plots represent estimates of the fluctuating streamwise velocity component. 
Considering both the mean streamwise velocity and $U^{\prime}$ profile plots in Fig. 12, there are clearly changes of behavior between the lower and higher blowing rate data. What is unclear, however, is if this change in behavior is strongly influenced by the change in wall temperature. To determine the extent to which both the streamwise velocity and $U^{\prime}$ profiles depend on wall temperature effects relative to increased blowing rate, a comparison between the mean velocity and $U$, profiles for two similar high $\dot{m}_{\text {Blowing }}$ values and two similar low $\dot{m}_{\text {Blowing }}$ values is made in Fig. 13. The profiles presented in this figure were each obtained at different times during a single wind tunnel run, resulting in significantly different (i.e. > $50 \mathrm{~K}$ ) measured wall temperatures during each acquisition period.

Based on the analysis of the data presented in Fig. 13, two important trends are observed. First, for the 'low' blowing rate data, the mean velocity profiles obtained with different surface temperatures nearly fall on top of one another over most f the boundary layer. The profile obtai

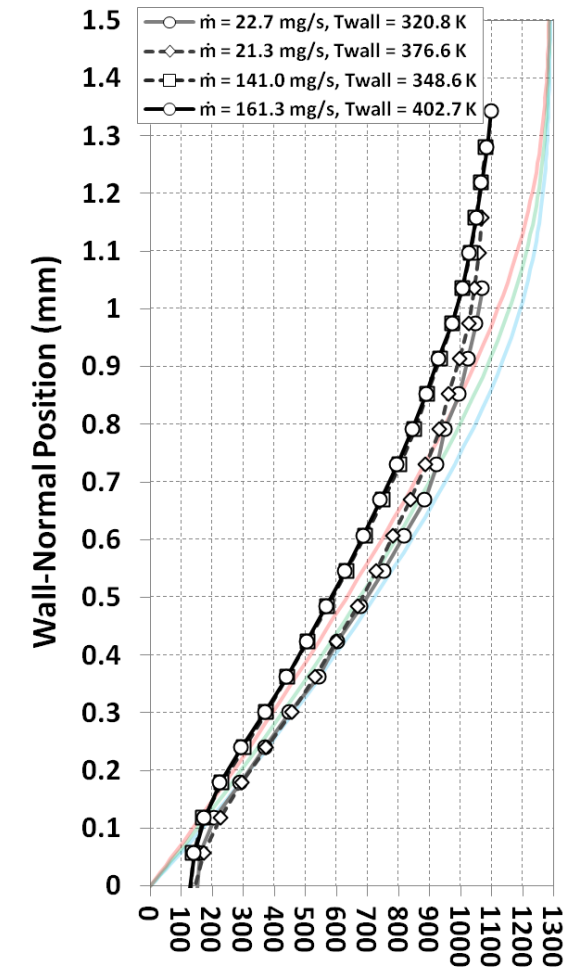

Mean Streamwise Velocity (m/

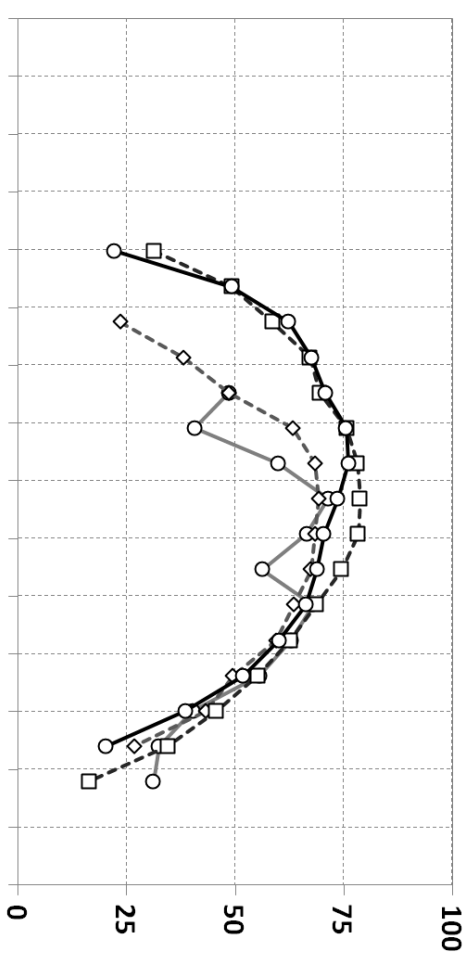

$U^{\prime}(m / s)$
Figure 13. Mean streamwise velocity profiles (left) and fluctuating streamwise velocity component profiles (right) for both low $(22.7 \mathrm{mg} / \mathrm{s}$ and $21.3 \mathrm{mg} / \mathrm{s})$ and high $(141.0 \mathrm{mg} / \mathrm{s}$ and $161.3 \mathrm{mg} / \mathrm{s})$ blowing rates, but with different wall temperatures for the low blowing rate $(320.8 \mathrm{~K}$ and $376.6 \mathrm{~K})$ and high blowing rate $(348.6 \mathrm{~K}$ and 402.7 K) data. $0.60 \mathrm{~mm}$, the 'low' $\dot{m}_{\text {Blowing }}=21.3 \mathrm{mg} / \mathrm{s}(0.684 \mathrm{SLPM})$ blowing rate profile $\left(T_{\text {wall }}=376.6 \mathrm{~K}\right)$ exhibits a slight velocity deficit relative to the $\dot{m}_{\text {Blowing }}=22.7 \mathrm{mg} / \mathrm{s}(0.723 \mathrm{SLPM})$ blowing rate profile $\left(T_{\text {wall }}=320.8 \mathrm{~K}\right)$. For the 'high' blowing rate data, both profiles fall nearly on top of one another over the extent of the measurement region; the effect of increasing wall temperature appears to be negligible in this case. Second, considering the $U$ ' data, the two 'high' blowing rate profiles exhibit the same general shape and distribution. At the 'low' blowing rates, the shapes and distributions of the $U$ ' profiles are similar to each other. However, the profile corresponding to the lower of the two wall temperatures $\left(\dot{m}_{\text {Blowing }}=22.7 \mathrm{mg} / \mathrm{s} ; T_{\text {wall }}=320.8 \mathrm{~K}\right.$ ) is more sporadic. In this comparison, it should again be noted that there is some error in the accuracy of the vertical placement of the data with respect to the model surface.

Based upon these trends, two important conclusions are made. First, the influence of the wall temperature on the mean streamwise velocity profiles for this experiment is smaller than that predicted by the analytic solutions. This could potentially be a consequence of the quartz window insert (an insulator) or perhaps localized cooling of the wall resulting from blowing of $\mathrm{NO}_{2}$. Second, the higher blowing rate has a noticeable effect on the mean streamwise velocity distribution and the intensity of velocity fluctuations in the boundary layer which is more significant than the relatively minor effect of the observed increase in wall temperature over the course of a wind tunnel run.

With knowledge of the limited effect wall temperature has on streamwise velocity, a functional relationship between the mean streamwise velocity distributions, the fluctuating component of streamwise velocity, and blowing rate can be developed. Figure 14 provides a comparison of measured mean streamwise velocity profiles (left plot) and estimated fluctuating streamwise velocity component profiles (right plot) for several blowing rates at a streamwise location $114.4 \mathrm{~mm}$ downstream of the leading edge.

The general effect of increasing the blowing rate on the measured streamwise velocity profile is an increase in the concentration boundary layer thickness with an accompanying decrease in measured velocity along the extent of the profile. This behavior is most pronounced for the profiles with blowing rates above $62.6 \mathrm{mg} / \mathrm{s}$ (2.010 SLPM), and is a potential result of several factors. First, the presence of the relatively cold, low velocity gas jet issuing from 
the seeding slot can form a complex separation region just ahead of the insert, a separation shock as a consequence of this separation region, and a primary bow shock. ${ }^{18}$ These structures, in turn, create local changes to the streamwise momentum and temperature fields. Once the oncoming boundary layer gas has been processed by these structures, it undergoes some level of mixing with the injected gas and a additional momentum and heat transfer processes occur. The gas then proceeds downstream and into the measurement region. In all of the mean streamwise velocity profiles, the magnitude of velocity at the edge of the measurement region is nearly $15 \%$ less than that predicted by the analytic solutions. This could be caused by the above mentioned bias error.

A the general shape of the $U$, profile remains the same for all blowing rates. However, the thickness of the profile appears to be roughly proportional to the blowing rate. As the rate is increased, the

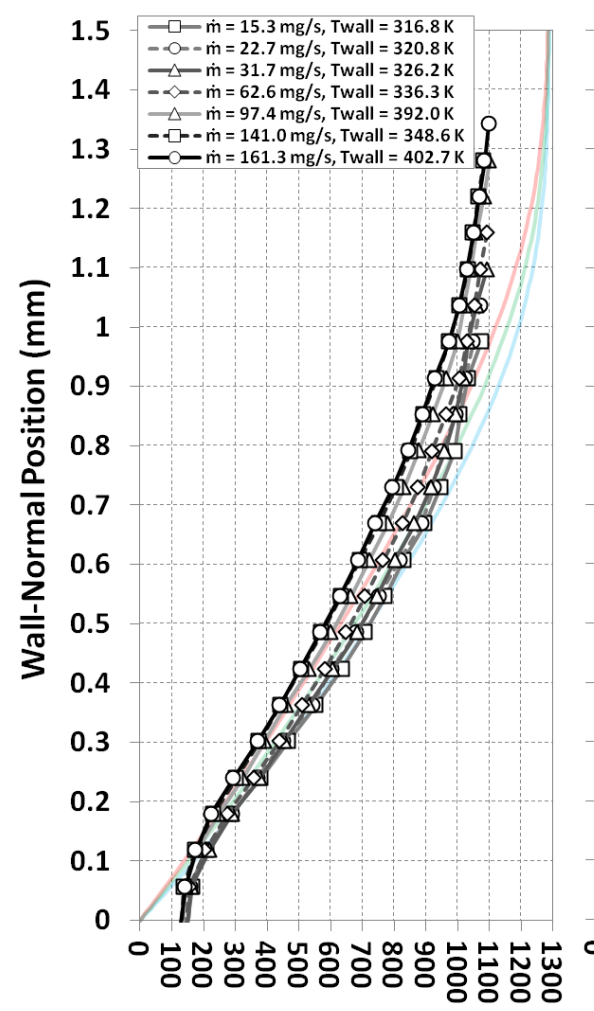

Mean Streamwise Velocity $(\mathrm{m} / \mathrm{s})$

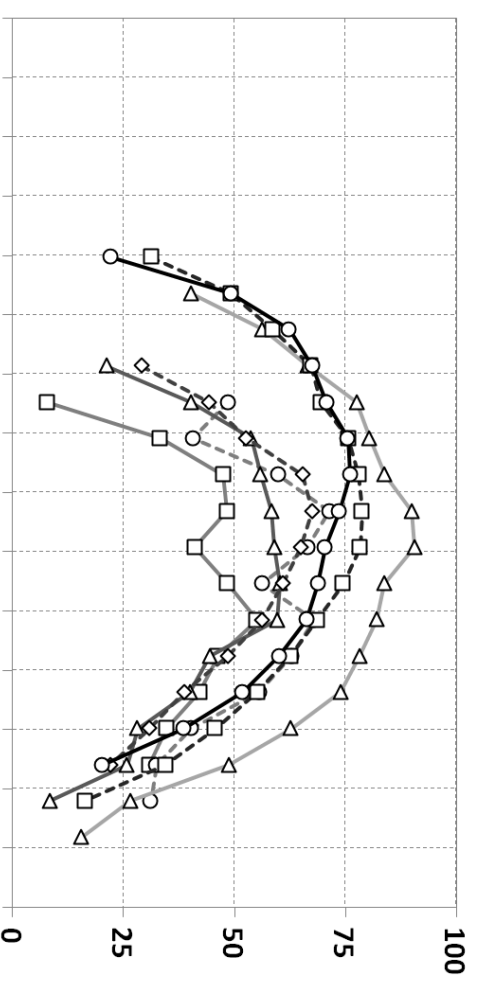

$U^{\prime}(\mathrm{m} / \mathrm{s})$
Figure 14. Mean streamwise velocity profiles (left) and fluctuating streamwise velocity component profiles (right) for several blowing rates.

profiles also become more parabolic in nature and the smoothness of the profiles becomes more pronounced. A noticeable jump in the thickness of the $U^{\prime}$ profiles seem to occur when the blowing rate is increased beyond 62.6 $\mathrm{mg} / \mathrm{s}$. At the highest blowing rate $\left(\dot{m}_{\text {Blowing }}=161.3 \mathrm{mg} / \mathrm{s}\right)$, the location of the peak $U^{\prime}$ values are at $50 \%$ of the velocity boundary layer thickness.

The plots in Fig. 14 show an important trend. For blowing rates beyond approximately $60 \mathrm{mg} / \mathrm{s}$, and at these specific experimental conditions, both the mean streamwise velocity profile and $U^{\prime}$ profile are noticeably affected by the blowing rate. This observation is important for two reasons. First, the initial motivation for using the $\mathrm{NO}_{2}$-toNO photolysis technique was mainly to study hypersonic boundary layer transition. The observation therefore highlights the blowing rate beyond which significant changes to the measured velocity boundary layer occur. Beyond this particular value, any increase in blowing rate may strongly influence the transition behavior. Second, as described in the introduction section, a general observation was made that as blowing rate increased, the signal-to-noise levels improved across the measurement region. In the previous study (Ref. 13), the signal-to-noise levels limited the overall data yield, both along the individual profiles and for profiles at streamwise locations away from the peak laser intensity regions. Since a requirement of the $\mathrm{NO}_{2}$-to-NO photolysis

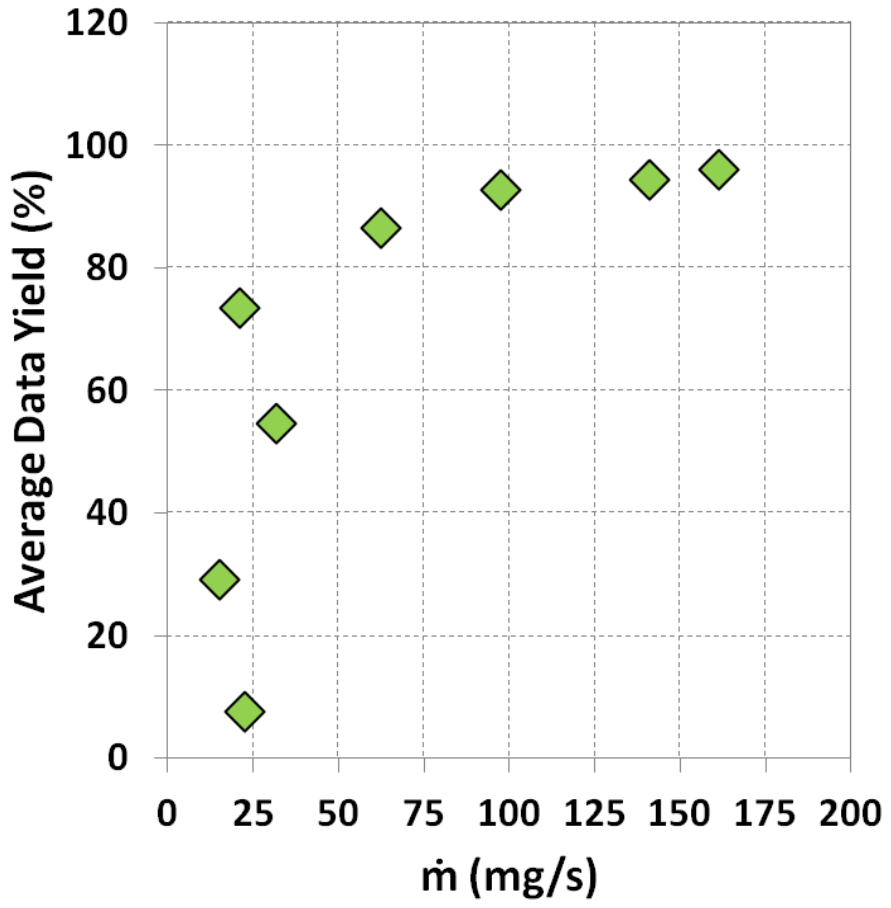

Figure 15. Average data yield as a function of $\dot{\mathrm{m}}_{\text {Blowing. }}$. 
technique, from the perspective of transition research, is to provide accurate information regarding the development of instabilities in both the wall-normal and streamwise directions, sufficient signal-to-noise levels are necessary across the entire measurement region. However, a tradeoff must be made between ensuring adequate signal-to-noise levels across the measurement region and minimizing the effect blowing rate has on the measured quantity.

Figure 15 plots the average data yield between $0.05 \mathrm{~mm}$ and $0.60 \mathrm{~mm}$ along the profile located at $123.5 \mathrm{~mm}$ downstream of the leading edge as a function of blowing rate. This was the profile farthest downstream of the leading edge for which velocity measurements were made in this experiment. The plot shows that for an adequate data yield across the streamwise extent of the measurement region, an approximate flow rate of at least $60 \mathrm{mg} / \mathrm{s}$ is required. This, in addition to the trends observed in Fig. 14, suggests that an optimal blowing rate for this particular set of conditions is approximately $60 \mathrm{mg} / \mathrm{s}$.

The top left-hand plot Fig. 16 shows several instantaneous profiles (colored data points) superimposed on top of the measured mean velocity profile (white data points with black uncertainty bands) for $\dot{m}_{\text {Blowing }}=161.3 \mathrm{mg} / \mathrm{s}$. Again, the probe delay for these data was $\Delta t_{P R O B E}=1 \mu \mathrm{s}$. The measured average wall temperature for these data was 402.7 $\mathrm{K}$. The analytic velocity boundary layer solution is provided for reference (light red solid line) for a wall temperature of $420 \mathrm{~K}$. The remaining plots show each of the instantaneous velocity profiles, along with their uncertainty bands (which are partially determined from the data presented in Fig. 4), plotted with the mean velocity profile.

In this figure, both near and far from the wall, the instantaneous profiles coincide closely with the measured mean velocity profile. Near the middle portion of the profile, however, noticeable deviations of the single-shot profiles from the mean velocity profile occur. Observation of the raw instantaneous images shows that on an intermittent basis, relatively sharp bends in the velocity profiles occur, resulting in significant localized deviations from the mean streamwise velocity. These images also show that the thickness of the concentration boundary layer also oscillates in the wall-normal direction. The occurrence of these deviations and oscillations appears to be random, at least when observed with a $10 \mathrm{~Hz}$ data rate.

In Fig. 14, the $U^{\prime}$ profile corresponding to $\dot{m}_{\text {Blowing }}=161.3 \mathrm{mg} / \mathrm{s}$ at $114.4 \mathrm{~mm}$ downstream of the leading edge shows, on average, how the instantaneous streamwise velocity profiles behave. Based on observation of the limited number of instantaneous profiles presented in Fig. 16, it may be that a pattern, consisting of several distinct locations at which velocity peaks occur relative to the mean profile, may exist.

One feature of significance in Fig. 16 is the magnitude of the instantaneous streamwise velocity uncertainties. For data between $0.05 \mathrm{~mm}$ and $0.60 \mathrm{~mm}$ along the profile located $114.4 \mathrm{~mm}$ downstream of the leading edge (image pair 1051), the average instantaneous uncertainty in velocity for the profiles shown was $68 \mathrm{~m} / \mathrm{s}$. This represents a reduction in instantaneous velocity uncertainty by more than a factor of 2.5 compared to the uncertainties computed for a laminar boundary layer that were presented in Fig. 10 of Ref. 13. Furthermore, some instantaneous measurements showed uncertainties as low as $44 \mathrm{~m} / \mathrm{s}$. Table 2 lists the average of the instantaneous uncertainty terms in the averaged region and their corresponding magnitudes as a percentage of the edge velocity for the image pair 1051 shown in Fig. 16. For this particular image pair, the single-shot uncertainty in this region was less than 5\% of the edge velocity. Further reductions in the single-shot uncertainty for this profile could be obtained by increasing the signal-to-noise levels and increasing the probe laser delay, $\Delta t_{P R O B E}$. If the signal-to-noise ratio was increased beyond 14 , the resulting single-shot uncertainty would be reduced by nearly a factor of 2 . Increasing the probe laser delay to $\Delta t_{P R O B E}=2 \mu \mathrm{s}$ would result in a further factor of 2 reduction in single-shot uncertainty according to Figs. 4 and 6.

Table 2. Average single-shot uncertainty between $Y=0.05 \mathrm{~mm}$ and $0.60 \mathrm{~mm}, X=114.4$ $\mathrm{mm}$, for image pair 1051 as a percentage of edge velocity.

\begin{tabular}{cc}
\hline \hline Uncertainty Term & \% of Edge Velocity $(1289 \mathrm{~m} / \mathrm{s})$ \\
\hline$u_{\text {Accuracy }}$ & 0.95 \\
$u_{\text {Magnification }}$ & 0.11 \\
$u_{U, \Delta x}$ & 4.84 \\
$u_{U, \Delta t}$ & 0.04 \\
$u_{U}=\sqrt{u_{\text {Accuracy }}^{2}+u_{\text {Magnification }}^{2}+u_{U, \Delta x}^{2}+u_{U, \Delta t}^{2}}$ & 4.91 \\
\hline \hline
\end{tabular}




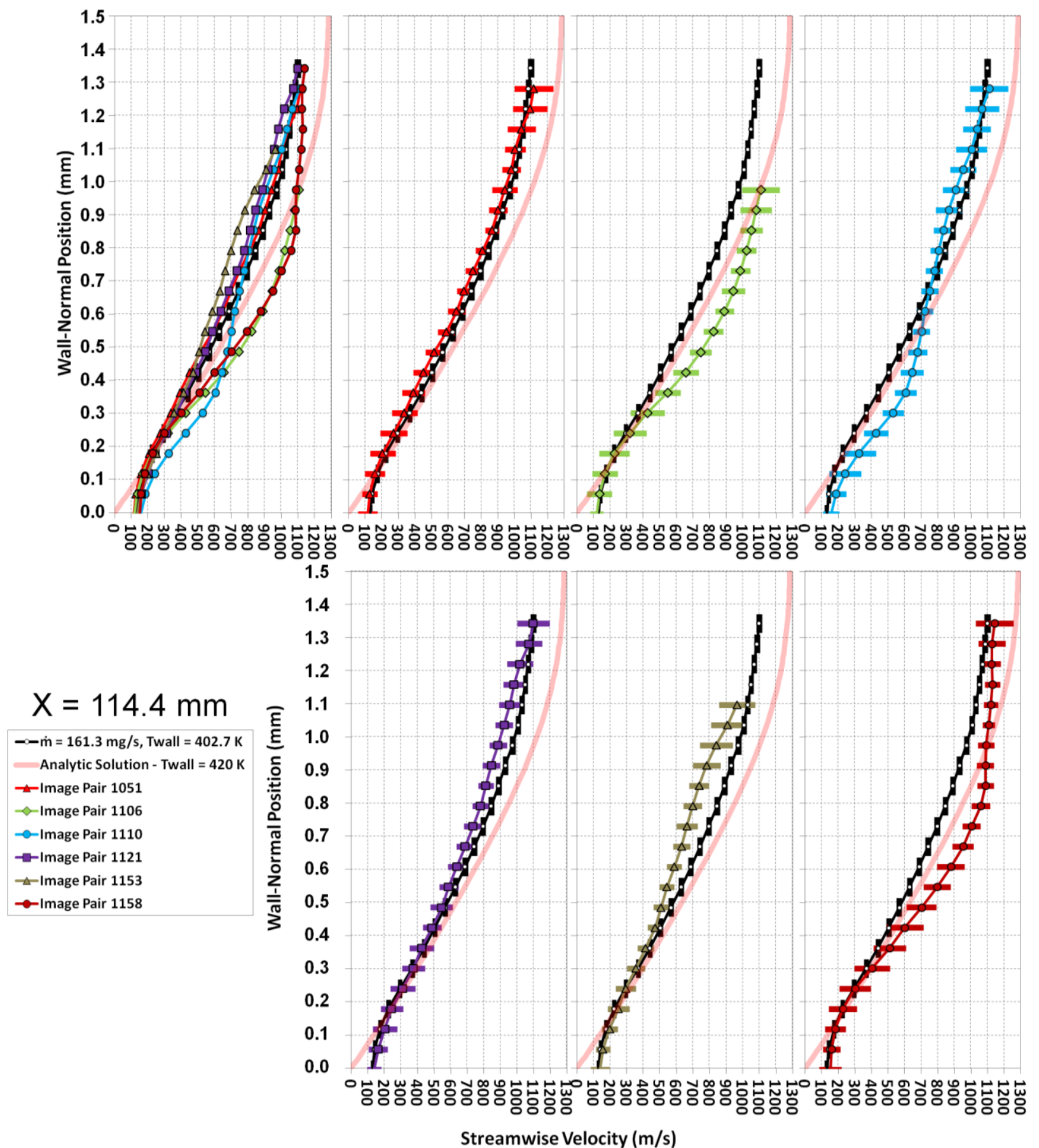

Figure 16. Mean and instantaneous velocity profiles obtained $114.4 \mathrm{~mm}$ downstream of the leading edge for $\dot{m}_{\text {Blowing }}=161.3$ $\mathrm{mg} / \mathrm{s} . \triangle t_{P R O B E}=1 \mu \mathrm{s}$. 


\section{Recommendations}

One aspect of the current work that was held constant for each of the experimental analyses was the location of the seeding slot on the model from which the $\mathrm{NO}_{2}$ was blown into the boundary layer. The location of the slot likely affected the thickness of the concentration boundary layer relative to the velocity boundary layer for all of the experiments. To achieve a concentration layer with a thickness more closely matching that of the velocity boundary layer thickness, experiments could be performed in which the seeding slot location is moved further upstream. Since doing this could potentially affect the stability of the boundary layer itself, an analysis of stability as a function of slot location would need to be performed.

Future velocity measurement experiments should utilize a $\triangle t_{P R O B E}$ setting of $2 \mu \mathrm{s}$ rather than $1 \mu \mathrm{s}$. While this reduces the spatial resolution of the measurement by a factor of 2, the single-shot uncertainty is also reduced by a factor of 2. Efforts should also be made to further improve the experimental signal-to-noise levels, in addition to those described in this paper, in order to further increase measurement precision.

The measured velocity profiles presented in this paper did not tend toward zero velocity at the wall. By improving the imaging system magnification, the spatial resolution of the experiment would be improved. This would allow for a better resolved velocity profile, especially near the plate surface. This would in turn make the measurement less susceptible to potential errors caused by pixel blooming.

In this paper, a primary goal was to analyze how the streamwise velocity profiles behaved as a function of blowing rate. While performing this analysis, we observed transient behavior of the concentration layer thickness. We hypothesize that these fluctuations in thickness lead to a random error that biases measurements near the edge of the boundary layer toward lower values of velocity. While a time-resolved CFD analysis could simulate and account for these errors, any future experimental work should include an analysis of the instantaneous images so that a parameter describing the unsteadiness of the concentration layer thickness may be obtained. This could be done by tracking the upper edge of the zero-delay instantaneous profiles on a frame-by-frame basis.

Future experiments should also include measurements characterizing the flow behavior in the region immediately surrounding the seeding slot. This should be done for a range of blowing rates to determine the kinds of flow structures present, as well as to provide quantitative descriptions of the magnitudes and fluctuating components of both dynamic and thermodynamic properties in this region. Such measurements could then be compared and possibly correlated with flow properties measured downstream of the seeding region (such as the streamwise velocity behavior measured in this paper). This could provide a better overall description of the seeding process used to make $\mathrm{NO}_{2}$-to-NO photolysis molecular tagging velocimetry measurements.

Finally, based on observation of the instantaneous profiles presented in Fig. 16, an analysis could be performed to determine if a predictable pattern exists in the vertical locations of maximum deviation from the mean velocity. Such a pattern could also potentially be related to any oscillation behavior of the concentration layer thickness. Such patters might also indicate instability modes in the boundary layer that would be instructive for transition studies.

While initial CFD analyses of this experiment should assume a sharp-leading-edge metallic flat plate at a constant temperature, a more detailed analysis could be performed that captured the model more precisely: the leading edge being solid steel, the top plate being a $1 / 5$ inch thick steel plate, and the quartz window where the measurement was performed being a 1/2 inch thick round quartz window. The time history of the model during the run could also be modeled to determine the temperature of the model surface. In future experiments, temperature sensitive paint could be used to determine the surface temperature of the metal model (and possibly the quartz window) during the run.

\section{Conclusions}

An experiment using $\mathrm{NO}_{2}$-to-NO photolysis molecular tagging velocimetry has been performed to determine how seeding of $\mathrm{NO}_{2}$ from a spanwise slot at various blowing rates a single streamwise location affects the behavior of the mean streamwise velocity and fluctuation streamwise velocity component profiles. Modifications to both the PLIF system and wind tunnel model, based upon observations made in previous experimental efforts, have resulted in significant improvements in signal-to-noise levels and reductions in experimental uncertainties by approximately a factor of 2, resulting in single-shot $95 \%$ confidence measurement uncertainties as low as $44 \mathrm{~m} / \mathrm{s}$ in the boundary layer flows. Suggestions for further reducing the uncertainty were discussed for future experiments. For the conditions tested in this experiment, a blowing rate threshold has been proposed, above which significant alterations to the mean streamwise velocity and fluctuating streamwise velocity component profiles were observed. 


\section{Acknowledgements}

We wish to acknowledge the contribution to this project from the NASA Langley Research Center 31-Inch Mach 10 Air Tunnel technicians and engineers, including Kevin Hollingsworth, Sheila Wright, Tony Robbins, Henry Fitzgerald and Johnny Ellis. In addition, we would like to acknowledge Andrew Lutz of the University of Vermont, who assisted in the setup of the experiment. Dr. Johansen was supported by the Natural Sciences and Engineering Research Council of Canada.

\section{References}

${ }^{1}$ Anderson, J.D., Hypersonic and High-Temperature Gas Dynamics, 2nd ed., AIAA, Reston, VA, 2006, pp. 327 $335 ; 559-573$.

${ }^{2}$ Berry, S.A., and Horvath, T.J., "Discrete Roughness Transition for Hypersonic Flight Vehicles," $45^{\text {th }}$ AIAA Aerospace Sciences Meeting, AIAA Paper 2007-0307, Reno, NV, January 8-11, 2007.

${ }^{3}$ Schubauer, G.B. and Skramstad, H.K., "Laminar Boundary-Layer Oscillations and Stability of Laminar Flow," Journal of the Aeronautical Sciences, 14(2), pp. 88-97, February, 1947.

${ }^{4}$ Schetz, J.A., Boundary Layer Analysis, 1st ed., Prentice-Hall, 1993, Englewood Cliffs, NJ, pp. 180-186.

${ }^{5}$ Bathel, B.F., Danehy, P.M., Inman, J.A., Jones, S.B., Ivey, C.B., and Goyne, C.P., "Velocity Profile Measurements in Hypersonic Flows Using Sequentially-Imaged Fluorescence-Based Molecular Tagging Velocimetry," AIAA Journal, Vol. 49, No. 9, September 2011. doi: 10.2514/1.J050722

${ }^{6}$ Bathel, B.F., Danehy, P.M., Inman, J.A., Watkins, A.N., Jones, S.B., Lipford, W.E., Goodman, K.Z., Ivey, C.B., and Goyne, C.P., "Hypersonic Laminar Boundary Layer Velocimetry with Discrete Roughness on a Flat Plate," AIAA Paper 2010-4998, 40th Fluid Dynamics Conference and Exhibit, Chicago, IL, June 28 - July 1, 2010.

${ }^{7}$ Orlemann, C., Schulz, C., and Wolfrum, J., "NO-flow tagging by photodissociation of NO2. A new approach for measuring small-scale flow structures," Chem. Phys. Lett., 307, pp. 15-20, 1999.

${ }^{8}$ Shinji, N., Kasahara, M., Tsue, M., and Kono, M., "Velocity Measurements of Reactive and Non-reactive Flows by NO-LIF Method Using NO2 Photodissociation," Heat Transfer - Asian Research, 34 (1), pp. 40-52, 2005. doi: $10.1002 / \mathrm{htj} .20038$

${ }^{9}$ Hsu, A.G., Srinivasan, R., Bowersox, R.D.W., and North, S.W., "Two-component molecular tagging velocimetry utilizing NO fluorescence lifetime and NO2 photodissociation techniques in an underexpanded jet flowfield," Applied Optics, 48 (22), pp. 4414-4423, August, 2009.

${ }^{10}$ Hsu, A.G., Srinivasan, R., Bowersox, R.D.W, and North, S.W., "Molecular Tagging Using Vibrationally Excited Nitric Oxide in an Underexpanded Jet Flowfield," AIAA Journal, 47 (11), pp. 2597-2604, November, 2009. doi: $10.2514 / 1.47716$

${ }^{11}$ Jiang, N., Nishihara, M., and Lempert, W.R., "500 kHz NO2 Molecular Tagging Velocimetry in a Mach 5 Wind Tunnel," AIAA 2010-4348, 27th AIAA Aerodynamic Measurement Technology and Ground Testing Conference, Chicago, IL, June 28 - July 1, 2010.

12 Sanchez-Gonzalez, R., Bowersox, R.D.W., and North, S.W., "Simultaneous velocity and temperature measurements in gaseous flowfields using the vibrationally excited nitric oxide monitoring technique: a comprehensive study," Applied Optics, 51(9), pp. 1216-1228, March 20, 2012. doi: 10.1364/AO.51.

${ }^{13}$ Bathel, B.F., Johansen, C.T., Danehy, P.M., Inman, J.A., Jones, S.B., and Goyne, C.P., "Hypersonic Boundary Layer Transition Measurements Using $\mathrm{NO}_{2} \rightarrow \mathrm{NO}$ Photo-dissociation Tagging Velocimetry," AIAA Paper 20113246, $41^{\text {st }}$ AIAA Fluid Dynamics Conference and Exhibit, June 27-30, Honolulu, HI.

${ }^{14}$ Micol, J.R., "Langley Aerothermodynamic Facilities Complex: Enhancements and Testing Capabilities," AIAA 1998-0147, 36th AIAA Aerospace Sciences Meeting, January 12-15, 1998, Reno, Nevada.

${ }^{15}$ Vincenti, W.G. and Kruger Jr., C.H., Introduction to Physical Gas Dynamics, 2nd ed., John Wiley \& Sons, 1967, New York, NY, p. 428.

${ }^{16}$ Johansen, C.T. and Danehy, P.M., "Numerical investigation of PLIF gas seeding for hypersonic boundary layer flows," AIAA 2012-1057, $50^{\text {th }}$ AIAA Aerospace Sciences Meeting, January 9-12, 2012, Nashville, TN.

${ }^{17}$ Inman, J.A., Bathel, B.F., Johansen, C.T., Danehy, P.M., Jones, S.B., Gragg, J.G., and Splinter, S.C., "Nitric Oxide PLIF Measurements in the Hypersonic Materials Environmental Test System (HYMETS)," $49^{\text {th }}$ AIAA Aerospace Sciences Meeting, AIAA Paper 2011-1090, Orlando, FL, January 4-7, 2011.

${ }^{18}$ Berry, S.A., Nowak, R.J., and Horvath, T.J., "Boundary Layer Control for Hypersonic Airbreathing Vehicles," $34^{\text {th }}$ AIAA Fluid Dynamics Conference, AIAA Paper 2004-2246, Portland, OR, June 28 - July 1, 2004. 